Article

\title{
Assessment of the MODIS LAI Product Using Ground Measurement Data and HJ-1A/1B Imagery in the Meadow Steppe of Hulunber, China
}

\section{Zhenwang Li, Huan Tang, Xiaoping Xin *, Baohui Zhang and Dongliang Wang}

National Hulunber Grassland Ecosystem Observation and Research Station Institute of Agricultural Resources and Regional Planning, Chinese Academy of Agricultural Sciences, Beijing 100081, China; E-Mails: lizhenwang10@hotmail.com (Z.L.); tanghuan_2011@hotmail.com (H.T.); zhangbaohui@ caas.cn (B.Z.); WDLGIS@gmail.com (D.W.)

* Author to whom correspondence should be addressed; E-Mail: xinxiaoping@caas.cn; Tel.: +86-10-8210-9618; Fax: +86-10-8210-9625.

Received: 2 April 2014; in revised form: 23 June 2014 / Accepted: 23 June 2014 /

Published: 2 July 2014

Abstract: The leaf area index (LAI) is a crucial parameter of vegetation structure. It provides key information for earth surface process simulations and climate change research on the global and regional scales. Focusing on the meadow steppe in Hulunber, Inner Mongolia, China, the present study assessed the accuracy of the Moderate Resolution Imaging Spectroradiometer (MODIS) LAI product in the study area. First, seven field campaigns collecting ground-based measurements were conducted during the growing season in 2013, and 252 pairs of LAIs and spectra were collected. Then, seven scenes of high-resolution LAI maps were obtained from the corresponding $30 \mathrm{~m}$ Chinese HJ-1A/1B charge-coupled diode (CCD) images by employing a regression approach. Finally, comparisons between the MODIS LAI product and the high resolution LAI maps were made to determine the accuracy of the MODIS LAI product. Moreover, the corresponding $500 \mathrm{~m}$ MODIS LAI maps were derived from the daily MODIS surface reflectance product to support the findings using the $1 \mathrm{~km}$ HJ LAI product and the ground-based comparison. The results showed that, compared to the ground data, the MODIS LAI product followed a reasonable seasonal trajectory during the growing season. However, an anomaly existed at the beginning of the growing season. Also, a slight overestimation was found for the MODIS LAI product compared to the HJ-retrieved LAI maps. The average overestimation for the LAI was approximately $0.4 \mathrm{~m}^{2} / \mathrm{m}^{2}$, and the relative absolute errors of the product ranged from $10 \%-50 \%$. The overestimation at the beginning and end of the growing 
season was higher due to the interference of soil background and grass variation. The results of this study provide a comprehensive understanding of the accuracy of the regional MODIS LAI product for the Hulunber meadow steppe. This research is important for improving regional modeling and prediction of vegetation biogeochemical processes and earth system productivity.

Keywords: leaf area index (LAI); Moderate Resolution Imaging Spectroradiometer (MODIS); HJ-1A/1B; validation; meadow steppe; Hulunber

\section{Introduction}

The leaf area index (LAI), defined as the one-sided green leaf area per unit ground area [1,2], is closely associated with vegetative photosynthesis, transpiration, and the energy balance of the land surface $[3,4]$. This index plays an important role in modeling biological and physical processes and in earth system productivity [5,6]. To meet the demand for long-term and large-scale biophysical information about the terrestrial surface, standard LAI products are produced from data acquired by the Moderate Resolution Imaging Spectroradiometer (MODIS) onboard NASA's Earth Observing System (EOS) Terra platform [7,8]. Because MODIS LAI data products are available to the public and are used in global or regional biogeochemistry models, a well-supported and sustained validation program is needed to provide timely feedback to algorithm developers to produce superior products through iterative improvements [8].

The MODIS LAI products have become widely used on both global and regional scales since their release in 2000. Many subsequent efforts have been made to validate these products, and various levels of accuracy and uncertainty have been reported [9-13]. The BigFoot Project [14], which was funded by NASA's Terrestrial Ecology Program during 1999-2003, covered nine flux tower sites from Alaska to Brazil. These sites represented eight major biomes, which were used as a prototype effort to help validate the MODIS Land Science Team science products, including land cover, LAI, fraction of absorbed photosynthetic active radiation (fAPAR), and net primary production (NPP) [15-17]. The Validation of Land European Remote Sensing Instruments (VALERI) group [18], which was launched by the European Space Agency, covered 34 validation sites in 21 countries that represent various different biomes. This project focused on the formation of a pool of instrumentation and tools for ground measurements and processing. Effective methodology was developed to generate high spatial resolution biophysical variable maps from satellite images, which were used for the validation of moderate-resolution global products [15,19]. Aiming to define standard validation guidelines and protocols and to foster data and information exchange relevant to the validation of land products, one subgroup of the CEOS WGCV, the Land Product Validation (LPV) group, was established in 2000 [20]. This group played a key role in coordinating the land product validation process [15]. Based on the validation reports and algorithm refinements, as well as feedback from previous work, the MODIS LAI products were reprocessed in Collection 5 (or C5) and released in 2007. The previous collection, Collection 4 (C4), was generally found to feature significant overestimates and anomalous day-to-day variations that resulted in noisy seasonal dynamics compared to field 
observations $[17,21,22]$. The MODIS LAI C5 products attempt to address these issues by refining the radiative transfer (RT) simulations to improve the consistency of the MODIS and simulated surface reflectances. In C5, the LUTs (look up table) for all biomes were recalculated with a new stochastic RT model to better depict three-dimensional effects. Additionally, six biomes in the old C4 LAI/FPAR biome map were replaced with a new (C5) eight biome map (by splitting the deciduous and evergreen subclasses) to improve MODIS LAI retrievals in forested areas [23,24].

The validation of coarse-resolution (e.g., $1 \mathrm{~km}$ ) LAI products is not a straightforward task [10,25,26]. The $1 \mathrm{~km}$ resolution of the MODIS LAI products often far exceeds the plot size typically used for field measurements. Therefore, an elaborate ground-based sampling strategy is critical to an accurate assessment of uncertainties in the LAI product [26-28]. Additionally, a direct comparison between ground measurements and the corresponding MODIS products is unconvincing because of geolocation errors, vegetation heterogeneity, and the algorithm limitations of multiscale data [10,29]. Thus, an intermediate step involving a fine-resolution map of the variable of interest is introduced to diminish these effects. However, the uncertainties in the registration and atmospheric corrections for satellite images also have a great influence on the generation of reference maps. In addition, $\mathrm{Wu}$ and $\mathrm{Li}$ [30] found that the method of converting the fine-resolution LAI maps into low-resolution reference maps is also challenging.

This study evaluated the accuracy of the MODIS LAI C5 product (also called MODIS LAI product or LP DAAC MODIS LAI product in this paper) with ground observations of the grassland in Hulunber, Inner Mongolia, China. Utilizing ground data collected from seven field campaigns during the growing season and the seven corresponding scenes of HJ-1A/1B charge-coupled diode (CCD) images, 30-m resolution LAI maps were generated. The MODIS LAI product was then compared to the aggregated HJ LAI maps on the pixel and patch scales. Moreover, seven scenes of corresponding $500 \mathrm{~m}$ MODIS LAI maps were derived from the daily MODIS surface reflectance product to support the findings using the $1 \mathrm{~km}$ HJ LAI product and the ground-based comparison. The goal of this study was to provide a comprehensive understanding of the regional product accuracy for the Hulunber meadow steppe for improving the use of this product in ecosystem modeling and prediction.

\section{Experiment Descriptions}

\subsection{Site Description}

The field observations for this study were conducted at the Hulunber Grassland Ecosystem Observation and Research Station (Hulunber Station) from June to August 2013, which has an area of $3 \mathrm{~km} \times 3 \mathrm{~km}$, and were distributed around the eddy covariance flux tower. Hulunber Station is located in the middle of the Hulunber meadow steppe $\left(49^{\circ} 20^{\prime} 24^{\prime \prime} \mathrm{N}, 119^{\circ} 59^{\prime} 44^{\prime \prime} \mathrm{E}\right)$, which is approximately $30 \mathrm{~km}$ northeast of the Hailer District in Hulunber City, Inner Mongolia, China (Figure 1). The station is one of the sites included in the Validation Network of Remote Sensing Products in China (VRPC) [31] and was chosen as one of the sites used in constructing the global MODIS products validation ASCII 3 database. The average elevation at the site is $650 \mathrm{~m}$, and the site features a flat surface that does not vary by more than $20 \mathrm{~m}$ in elevation. The regional climate is characterized as a semiarid steppe with an annual average rainfall of 350-400 mm, which mainly occurs from July to September [32]. The land 
cover is meadow steppe, which is dominated by Leymus chinensis and Stipa baicalensis. There are three pasture types (Figure 1): grazing pasture, which feeds cattle; cutting pasture that is used for silage; and enclosed pasture, which is enclosed by a fence and has grown naturally for the past seven years without any external influence.

Figure 1. Site location and sampling points (background: Landsat-8 OLI false-color composite image $(5,4,3)$ from 13 June 2013). (a) Site location; (b) Sample points.

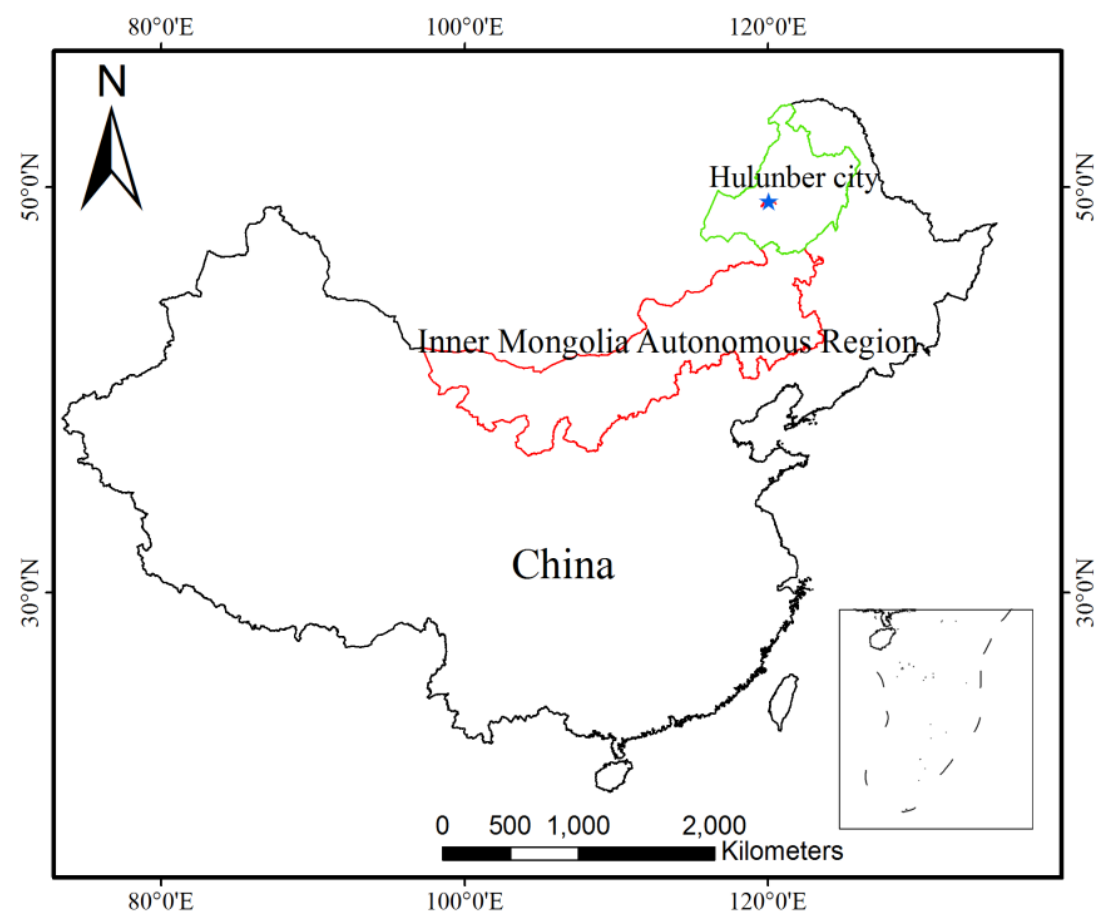

(a)

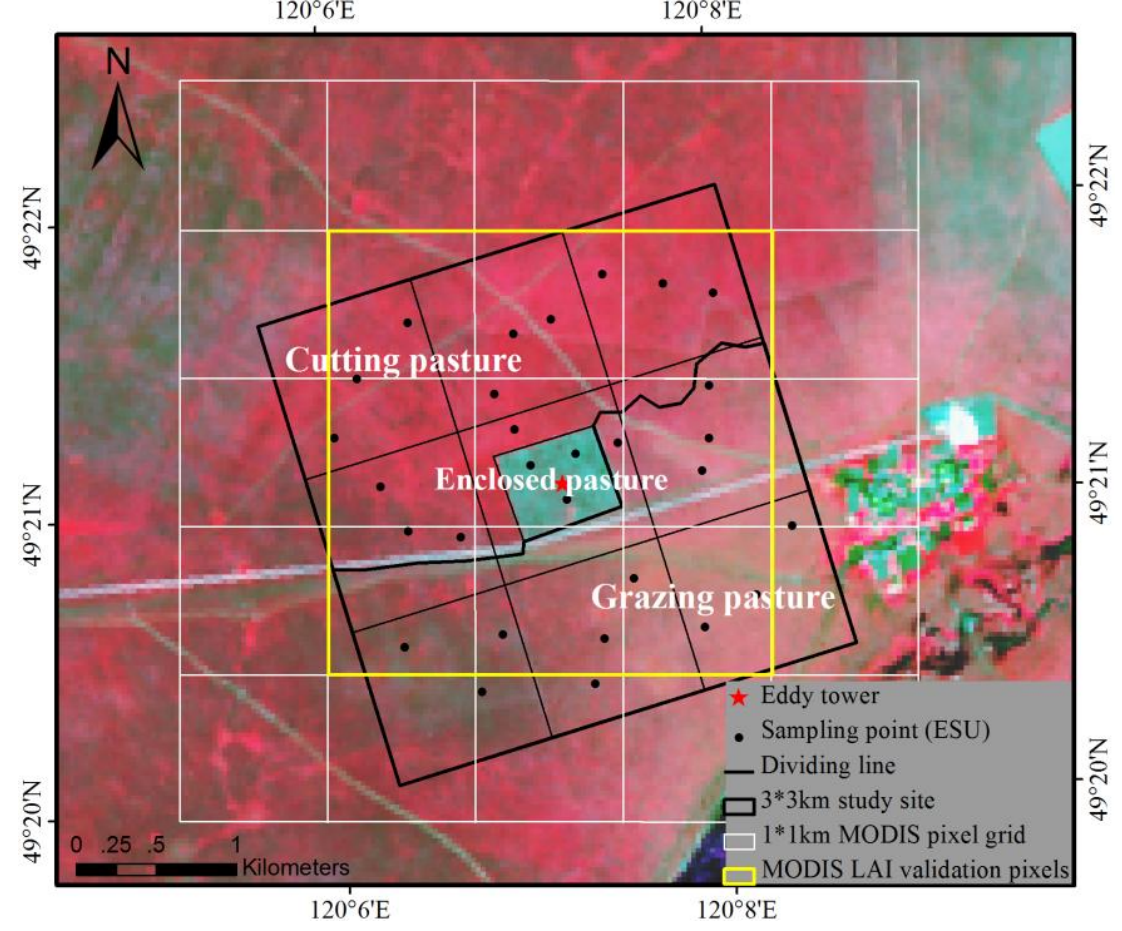

(b) 


\subsection{Sample Design and Field Measurements}

This study used a two-scale sampling strategy designed by the VALERI project to collect ground LAI and spectra data [19,21]. The two scales of the VALERI method were the site scale (at least a $3 \mathrm{~km} \times 3 \mathrm{~km}$ square) and the elementary sampling unit scale (ESU, $30 \mathrm{~m} \times 30 \mathrm{~m}$ in this study). The site scale referred to the entire experiment site, which reflected the ground conditions from the MODIS land products. The pixel size, homogeneity, topography and biome types were four factors that affected the accuracy of estimates of biophysical variables from ground measurements. The ESU scale corresponded to a high spatial resolution pixel size or a small cluster of those pixels. Their locations were globally chosen and equally proportioned for all the cover types present in the site and within one biome type. In this study, the $3 \mathrm{~km} \times 3 \mathrm{~km}$ site was divided into nine $1 \mathrm{~km} \times 1 \mathrm{~km}$ grids, and three ESUs were chosen in each grid. The central $1 \mathrm{~km}^{2}$ grid was more intensively sampled with five ESUs because it was more heterogeneous. Also, six additional ESUs were selected in the study site for a better representation around the site. In total, 36 ESUs were chosen across the entire site (Figure 1).

The effective LAI (the units are $\mathrm{m}^{2} / \mathrm{m}^{2}$ and will not be stated in the following sections) was measured with an LAI-2000 plant canopy analyzer (Li-Cor, Lincoln, Nebraska, USA). The LAI-2000 is an indirect non-contact instrument to measure the gap fraction that observe diffuse radiation transmission through the canopy [25,33,34]. Based on the assumption of a random leaf distribution within the canopy, the measured gap fraction data are inverted to obtain the effective LAI. At each ESU, the effective LAI was measured at five points organized in a "cross" pattern in which each sample point was $15 \mathrm{~m}$ from the next point (Figure 2). One above-canopy and six below-canopy LAI-2000 measurements were taken at each point to obtain one local LAI value, and five local LAI values were averaged to calculate a mean value for each ESU. The measurements were collected near sunrise or sunset to obtain nearly uniform sky illumination.

Figure 2. Field campaign sampling strategy for each ESU (left: LAI measurement; right: spectrum measurement).
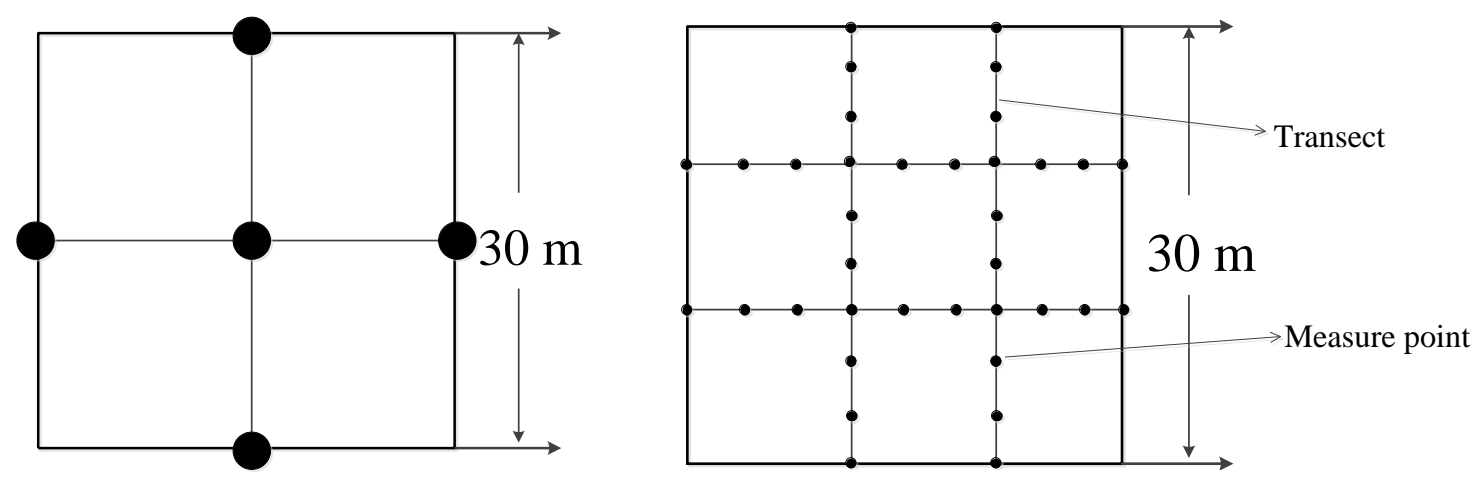

The relationship between the effective LAI $\left(\mathrm{L}_{\mathrm{E}}\right)$ and the true LAI is defined by Chen and Cihlar [35] as:

$$
L A I=(1-\alpha) L_{e} \gamma_{e} / \Omega_{e}
$$

where $\alpha$ is the woody-to-total area ratio, $\gamma_{e}$ is the needle-to-shoot area ratio, and $\Omega_{e}$ is the element clumping index. In the MODIS LAI algorithm, the grassland canopies exhibit vertical and lateral 
homogeneity, vegetation ground cover of approximately 1.0, erect leaf inclination, no woody material, and minimal leaf clumping [36]. Thus, in this study, we set $\alpha=0, \gamma_{e}=1$. The value of the element clumping index was set to 0.9 , which is an empirical coefficient used by Liu et al. [37] for mapping LAI for carbon cycle models from MODIS data.

The ground spectrum was measured using an ASD FieldSpec HandHeld Portable Spectroradiometer (Analytical Spectral Devices, Inc, Boulder, CO, USA) with a wavelength range of 325-1075 nm, a spectral resolution of less than $3.0 \mathrm{~nm}$, and a $25^{\circ}$ field-of-view. The measurements were collected near solar noon in clear conditions at the same location as the LAI using a flag landmark on the same day; the fiber was held $1.5 \mathrm{~m}$ above the canopy, and the probe was held vertically below. At each ESU, the measurement was organized in a series of transects forming a $2 \times 2$ grid, and 10-15 spectral curves were collected in each transect. In total, 40-50 spectral curves were collected and then averaged to represent each ESU's ground spectrum. In addition, the GPS locations, which were accurate to $2 \mathrm{~m}$, of each ESU were recorded at the center point. Prior to the field campaigns, the ASD Spectroradiometer was calibrated using a spectralon produced by the Anhui Institute of Optics and Fine Mechanics, Chinese Academy of Sciences.

\section{Data Analysis and LAI Mapping}

\subsection{In Situ LAI Data}

Histograms, mean LAI values, and standard deviations were used to determine the uncertainty of in situ-measured effective LAI values. Figure 3 presents the histograms of the field-measured effective LAI values for the entire site, the cutting pasture and the grazing pasture which were collected during every field campaign; good results are observed. The distribution of the measured LAI values for most dates forms an approximately normal distribution; the standard deviation is relatively small compared with the mean LAI values. Generally, the mean effective LAI values for the site were $0.9-2.5 \mathrm{~m}^{2} / \mathrm{m}^{2}$ during the growing season. For the cutting pasture, the maximum LAI value was $2.81 \mathrm{~m}^{2} / \mathrm{m}^{2}$ (standard deviation of $0.78 \mathrm{~m}^{2} / \mathrm{m}^{2}$ ), which occurred in the later stage of grass growth (19 August). The maximum LAI value for the grazing pasture was $1.81 \mathrm{~m}^{2} / \mathrm{m}^{2}$ (standard deviation of $0.29 \mathrm{~m}^{2} / \mathrm{m}^{2}$ ), which occurred on 6 July. During the peak of the growing season, the mean LAI value remained at $1.9-2.1 \mathrm{~m}^{2} / \mathrm{m}^{2}$ over entire site. On 19 August the standard deviation of the cutting pasture is $0.78 \mathrm{~m}^{2} / \mathrm{m}^{2}$, which was larger than the values of the other dates. This result was due to the grass cutting activity that occurred in this pasture.

\subsection{HJ-1A/B CCD Imagery and Preprocessing}

The HJ-1A/1B satellites are a new generation of small civilian Earth-observing satellites that were launched on 6 September 2008 by China [38]. Among the payloads aboard these two satellites, the multispectral CCD cameras are important instruments that are widely used in eco-environmental monitoring. Each satellite carries two CCD cameras, named CCD1 and CCD2, with a swath width of $700 \mathrm{~km}$ and a 48-h return period. The HJ-1A/1B CCDs have three visible bands (430-520 nm, $520-600 \mathrm{~nm}$ and 630-690 nm) and one near-IR band (760-900 nm) [39,40]. 
Figure 3. Distribution of the measured effective LAI values collected in different stage of the growing season. (a) 4 June; (b) 23 June; (c) 6 July; (d) 13 July; (e) 25 July; (f) 11 August; (g) 19 August.

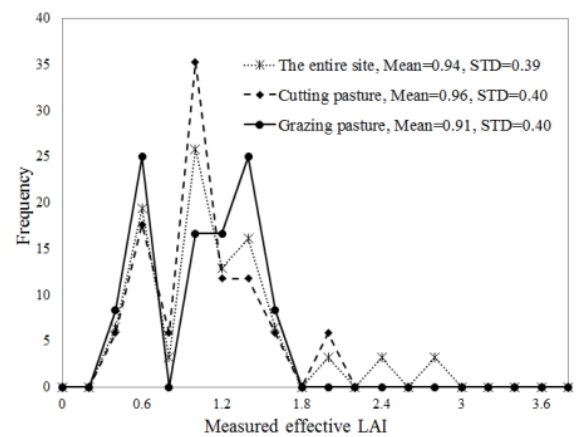

(a)

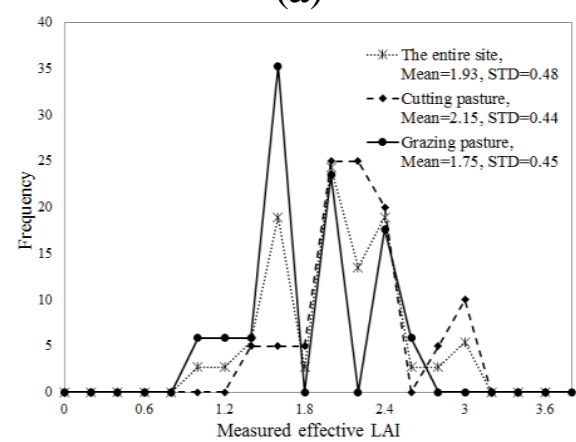

(d)

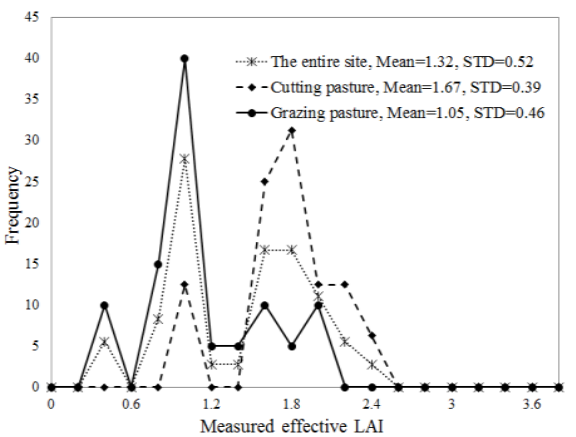

(b)

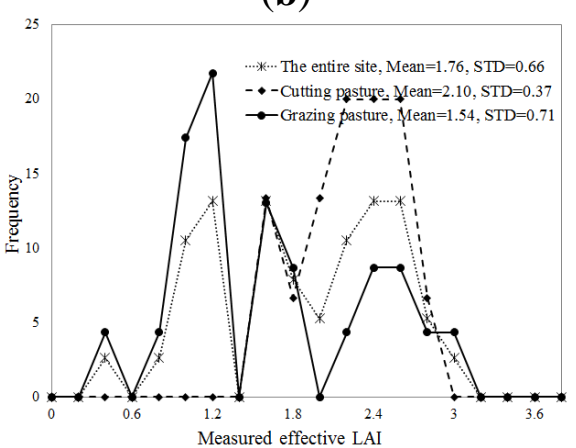

(e)

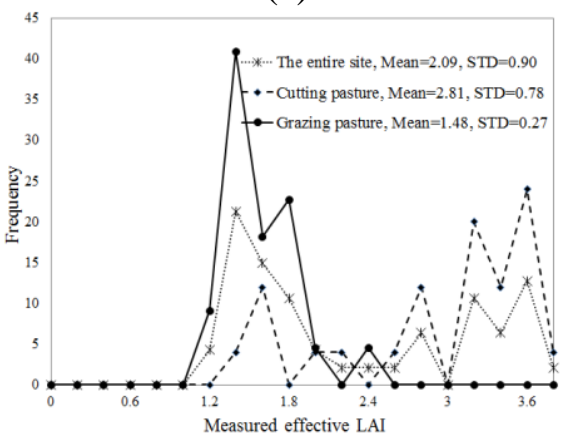

(g)

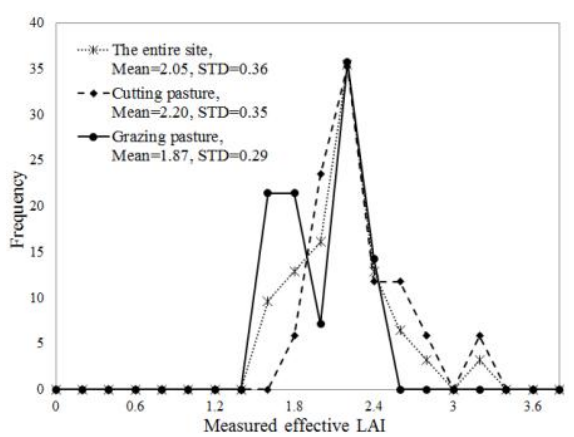

(c)

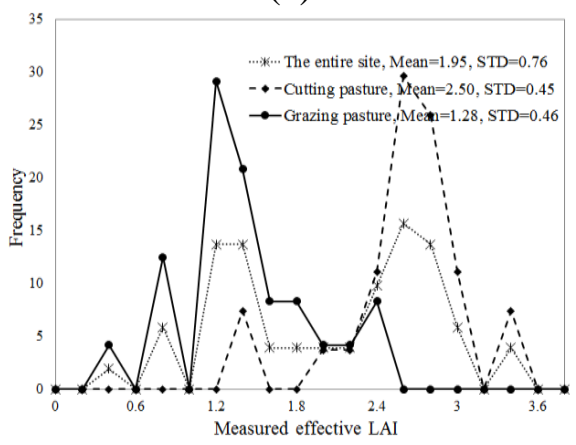

(f)

In this study, seven scenes of HJ-1A/1B CCD satellite images were collected, which correspond with the field data acquisition dates described in Table 1. The images received level 2 processing (radiometric correction and systematic geometric correction) and were projected in UTM coordinates (WGS84 datum, Zone 50N). All the images were high quality; minimal $(<10 \%)$ cloud or no cloud contamination occurred at site. Then, the images were atmospherically corrected using the FLAASH program embedded in the ENVI 4.8 software. FLAASH is a first-principle atmospheric correction program that incorporates the MODTRAN4 radiation transfer code to correct the wavelengths in the visible, near-infrared and shortwave infrared bands up to $3 \mathrm{~nm}$ [41]. An important parameter used in the FLAASH program for atmospheric correction is visibility, which can be calculated from aerosol optical depth at $550 \mathrm{~nm}$ [42]. The aerosol optical depth at $550 \mathrm{~nm}$ was obtained using the technique reported in [40]. Finally, the geometric correction was performed on all HJ-1A/1B CCD images using ground points collected in the field around the site; the correction accuracy was limited to within 1 pixel. 
Table 1. Acquired remote sensing images.

\begin{tabular}{cccc}
\hline $\begin{array}{c}\text { Experiment } \\
\text { Date }\end{array}$ & $\begin{array}{c}\text { Sensor for Acquired } \\
\text { HJ Images }\end{array}$ & HJ Image Date & $\begin{array}{c}\text { MODIS LAI Composition } \\
\text { Time-Interval }\end{array}$ \\
\hline 4-5 June & HJ1B-CCD1 & 4 June 2013 & 153-161 (2-10 June) \\
21-23 June & HJ1B-CCD1 & 23 June 2013 & 169-171 (18-26 June) \\
6-7 July & HJ1A-CCD1 & 6 July 2013 & 177-185 (26 June-4 July) \\
13-14 July & HJ1A-CCD2 & 13 July 2013 & 185-193 (4-12 July) \\
25-26 July & HJ1A-CCD2 & 21 July 2013 & 201-209 (20-28 July) \\
11-12 August & HJ1B-CCD2 & 11 August 2013 & 217-225 (5-13 August) \\
19-20 August & HJ1B-CCD2 & 19 August 2013 & 225-233 (13-21 August) \\
\hline
\end{tabular}

\subsection{MODIS Products and Preprocessing}

The MODIS Collection 5 LAI products (MOD15A2, H25V04) and MODIS land cover type products (MCD12Q1 V051, H25V04) were acquired in HDF format from the USGS's Land Processes Distributed Active Archive Center (LP DAAC) [43]. The LAI product has a resolution of $1 \mathrm{~km}$ and a time interval of 8 days, while land cover type products have a resolution of $500 \mathrm{~m}$ and a temporal coverage of 2012-2013. After reprojecting all the MODIS products to UTM coordinates (WGS84 datum) using the MODIS Reprojection Tool (MRT), 0.1 was added to the LAI products to produce the LAI values [44].

The FPAR/LAI quality assessment (QA) datasets specify the overall quality of the products and contain information about the status of the retrieval, such as the overall quality of the input data, the cloud conditions, and the algorithm used to retrieve the LAIs [28,44]; these datasets are included in the MOD15A2 products. Based on the acquired QA information of the site, the values of the "SCF" parameter in the bitfield of all 10 scenes were interpreted as "000". This value means that the LAI pixels that covered the site were all produced by the main algorithm. However, differences exist in the "cloud state" parameter of scenes 177-185 and 209-217 compared with the other scenes. The LAI pixels that covered the site of these two scenes were produced from cloud-contaminated reflectance products. The corresponding mean LAI values of these two scenes were abnormal and lower than the adjacent scenes. Pisek and Chen [45] reported that cloud contamination reduced the precision of surface reflectance products, which are important inputs of the MODIS LAI algorithms, and caused the main algorithm to produce a low LAI value. Therefore, these two abnormal scenes were excluded from the accuracy assessment of the MODIS LAI products.

The daily MODIS surface reflectance product (MOD09GA, collection 5) was also acquired to directly examine the MODIS LAI product in this study. This product was used to extract vegetation indices and map MODIS surface reflectance-based LAIs in the study region. The MOD09GA product used in this study has seven bands with a spatial resolution of $500 \mathrm{~m}$ and a daily gridded L2G process. After checking the QA information associated with the product, seven scenes of the MOD09GA product were collected on the same day as HJ-1A/1B CCD images with the highest product quality. 


\subsection{LAI Modeling and Mapping}

\subsubsection{Ground-Based LAI Modeling and $30 \mathrm{~m}$ HJ Retrieved LAI Mapping}

An empirical regression approach was employed to retrieve the effective LAI maps. Wang et al. [28] reported that empirical approaches worked well to produce a fine-resolution LAI map because the regression processes could find the best fit between the regressed variables and eliminate the problem of systematic bias at a specific site. Various vegetation indices are widely used and tested to regress ground-measured LAI, such as the Normalized Differential Vegetation Index (NDVI), Simple Ratio (SR) and Reduced Simple Ratio (RSR) [25,46,47]. Owing to the lack of a shortwave infrared reflectance channel in the HJ sensors, the RSR was not used in this study. Due to the radiation differences and geolocation errors within and between images, we used the field LAI data and field spectrum collected from in situ campaigns to build the regression model. Moreover, Chen et al. [25] found that an algorithm developed from multiple scenes is more reliable than that developed from only one scene due to the small dynamic range of the LAI and the insufficient number of data points in a single scene.

$$
\begin{gathered}
N D V I=\frac{\rho_{\text {nir }}-\rho_{\text {red }}}{\rho_{\text {nir }}+\rho_{\text {red }}} \\
S R=\frac{\rho_{\text {nir }}}{\rho_{\text {red }}}
\end{gathered}
$$

where $\rho_{\text {nir }}$ and $\rho_{\text {red }}$ are the reflectances in the near-infrared and red bands, respectively.

From seven field campaigns, a total of 252 pairs of LAIs and spectra were collected. After eliminating obviously erroneous data that had an LAI value deviation of 1.0 from the average, 242 pairs of data were used in this study. We separated the dataset into three groups: 120 pairs for modeling, 80 pairs to reduce radiation differences between the images and improve the model, and 42 pairs for validation. Each group should include pairs from all seven campaigns, and the range of the LAI should be representative. Finally, a convolution computation was implemented to transfer the ground spectra to the HJ image bands, and the NDVIs and the SRs were obtained for each ESU (Equations (2) and (3)).

Relationships were built through the regression between the 120 pairs of LAIs and vegetation indices (VI). The logarithmic relationships between the effective LAI and NDVI ( $R^{2}$ of 0.4961$)$ and the effective LAI and SR ( $R^{2}$ of 0.4814$)$ were found to be better than those of other regression types (Figure 4). By applying the relationships to the HJ images, the effective LAI maps were obtained. The average deviation from the field LAI was 0.4759 for NDVI (RMSE $=0.5994$ ) and 0.3513 for SR $(\mathrm{RMSE}=0.4383)$ using the 42 pairs of LAI validation data. However, uncertainty still existed due to the influence of non-photosynthetic vegetation and soil on the collected spectrums, which NDVI and SR cannot account for; eventually, these factors impact the regression model and LAI maps [25,28]. To reduce the errors introduced by the ground-measurement and regression model, another 80 pairs of ground measured LAI data were used to improve the comparability of the acquired LAI maps. Relationships were built between the retrieved LAIs and the 80 field-measured LAIs for every scene (Table 2). Using the same 42 pairs of LAI validation data for validation, an obvious improvement was 
obtained (Figure 5); the average deviation from the field LAI was improved from $0.4759-0.2845$ for NDVI (RMSE from 0.5994-0.3288) and from 0.3513-0.2899 for SR (RMSE from 0.4383-0.3387). The statistics of each scene's effective LAI map that was retrieved from the HJ images before and after the improvement are also shown in Table 2. The accuracy of all of the retrieved maps was improved to different extents. Most RMSEs of the post-improvement maps that are based on the in situ validation data range from $0.25 \mathrm{~m}^{2} / \mathrm{m}^{2}$ to $0.4 \mathrm{~m}^{2} / \mathrm{m}^{2}$. Due to the overall performance of all of the LAI maps and the fast saturation in estimations of the large LAI values of the LAI-SR model, the improved effective LAI maps acquired from the LAI-NDVI model were utilized to validate the accuracy of the MODIS LAI products.

Figure 4. Relationships between in situ LAI-NDVI (left) and LAI-SR (right).
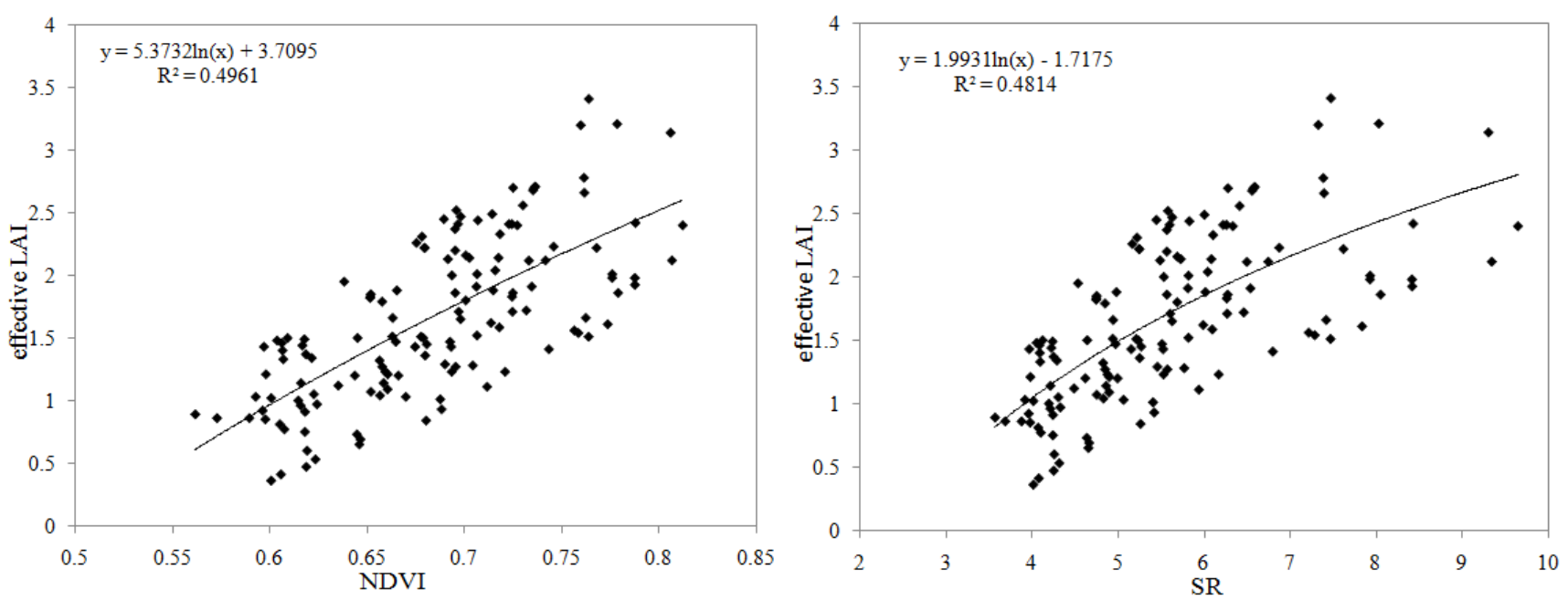

Table 2. Statistics of each scene's model-improved HuanJing (HJ) satellite retrieved effective LAI map.

\begin{tabular}{|c|c|c|c|c|c|c|c|c|}
\hline \multirow{2}{*}{ Date } & \multirow{2}{*}{ VI } & \multicolumn{4}{|c|}{ Model Improvement } & \multicolumn{3}{|c|}{ RMSE of Model Validation } \\
\hline & & $\mathbf{n}$ & Relationship & $\mathbf{R}^{2}$ & RMSE & $\mathbf{n}$ & Before & After \\
\hline \multirow{2}{*}{4 June } & NDVI & \multirow{2}{*}{10} & $\mathrm{LAI}_{\mathrm{aft}}=0.9521 \times \mathrm{LAI}_{\text {bef }}+0.1300$ & 0.7728 & 0.097 & \multirow{2}{*}{6} & 0.3369 & 0.3285 \\
\hline & SR & & $\mathrm{LAI}_{\mathrm{aft}}=0.6437 \times \mathrm{LAI}_{\text {bef }}+0.2455$ & 0.7565 & 0.145 & & 0.3635 & 0.3290 \\
\hline \multirow{2}{*}{23 June } & NDVI & \multirow{2}{*}{12} & $\mathrm{LAI}_{\mathrm{aft}}=0.6820 \times \mathrm{LAI}_{\text {bef }}+0.1157$ & 0.5558 & 0.38 & \multirow{2}{*}{6} & 0.3140 & 0.3744 \\
\hline & SR & & $\mathrm{LAI}_{\mathrm{aft}}=1.2773 \times \mathrm{LAI}_{\text {bef }}-1.1868$ & 0.5091 & 0.73 & & 0.5611 & 0.3827 \\
\hline \multirow{2}{*}{6 July } & NDVI & \multirow{2}{*}{10} & $\mathrm{LAI}_{\mathrm{aft}}=0.4912 \times \mathrm{LAI}_{\text {bef }}+0.9038$ & 0.7077 & 0.3 & \multirow{2}{*}{6} & 0.3938 & 0.3901 \\
\hline & SR & & $\mathrm{LAI}_{\text {aft }}=0.4844 \times \mathrm{LAI}_{\text {bef }}+0.7424$ & 0.7019 & 0.45 & & 0.3906 & 0.3861 \\
\hline \multirow{2}{*}{13 July } & NDVI & \multirow{2}{*}{10} & $\mathrm{LAI}_{\mathrm{aft}}=1.4786 \times \mathrm{LAI}_{\text {bef }}+0.2480$ & 0.6307 & 0.76 & \multirow{2}{*}{6} & 0.7646 & 0.2935 \\
\hline & SR & & $\mathrm{LAI}_{\text {aft }}=1.1136 \times \mathrm{LAI}_{\text {bef }}+0.3033$ & 0.6193 & 0.48 & & 0.4941 & 0.2754 \\
\hline \multirow{2}{*}{25 July } & NDVI & \multirow{2}{*}{13} & $\mathrm{LAI}_{\mathrm{aft}}=1.7577 \times \mathrm{LAI}_{\mathrm{bef}}-0.4161$ & 0.6574 & 0.64 & \multirow{2}{*}{6} & 0.6122 & 0.2672 \\
\hline & SR & & $\mathrm{LAI}_{\text {aft }}=1.4704 \times \mathrm{LAI}_{\text {bef }}-0.5354$ & 0.6578 & 0.42 & & 0.3235 & 0.2251 \\
\hline \multirow{2}{*}{11 August } & NDVI & \multirow{2}{*}{12} & $\mathrm{LAI}_{\mathrm{aft}}=2.7826 \times \mathrm{LAI}_{\text {bef }}-1.8614$ & 0.7673 & 0.76 & \multirow[b]{2}{*}{6} & 0.6092 & 0.3613 \\
\hline & SR & & $\mathrm{LAI}_{\mathrm{aft}}=2.5092 \times \mathrm{LAI}_{\text {bef }}-2.3680$ & 0.7764 & 0.54 & & 0.4289 & 0.3594 \\
\hline \multirow{2}{*}{19 August } & NDVI & \multirow{2}{*}{13} & $\mathrm{LAI}_{\mathrm{aft}}=1.7141 \times \mathrm{LAI}_{\text {bef }}-0.5404$ & 0.6299 & 0.69 & \multirow{2}{*}{6} & 0.6300 & 0.4228 \\
\hline & SR & & $\mathrm{LAI}_{\text {aft }}=1.5418 \times \mathrm{LAI}_{\text {bef }}-0.7854$ & 0.6518 & 0.63 & & 0.4763 & 0.4508 \\
\hline
\end{tabular}


Figure 5. Validation of the HJ-retrieved effective LAI maps before (left panel) and after (right panel) improvement. (a) Validation of the HJ-retrieved effective LAI maps before and after improvement using the LAI-NDVI model. (b) Validation of the HJ-retrieved effective LAI maps before and after improvement using the LAI-SR model.
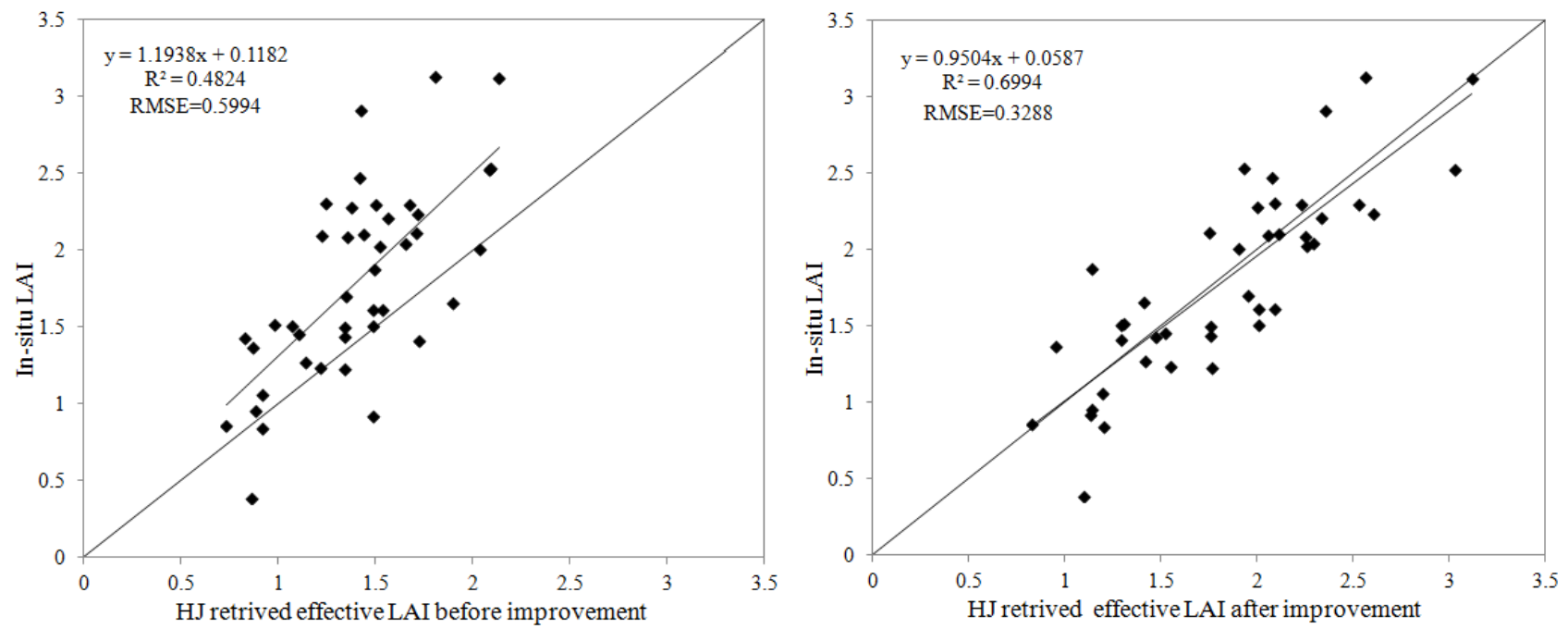

(a)
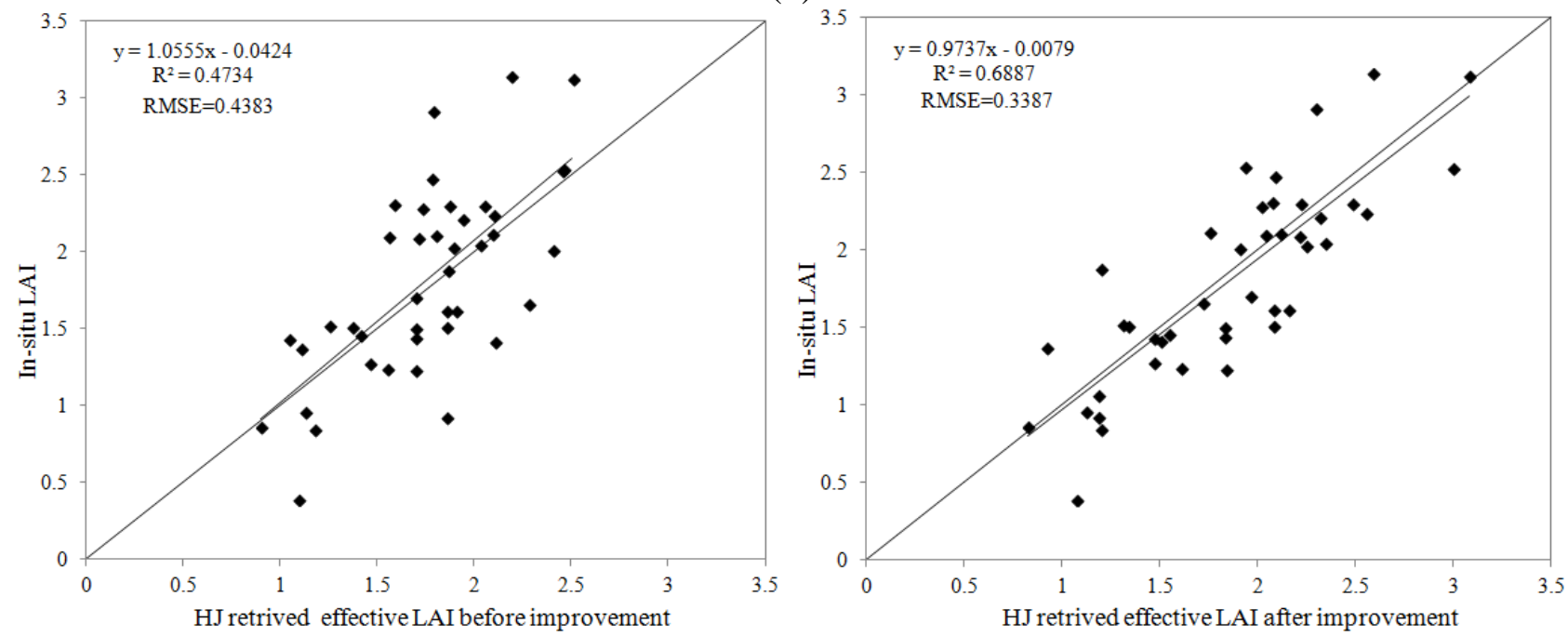

(b)

\subsubsection{MODIS Surface Reflectance-Based LAI Modeling and 500 m MODIS Retrieved LAI Mapping}

Additionally, an empirical approach was employed to retrieve the effective LAI maps; the vegetation indices used were NDVI and SR. After calculating the NDVI and SR maps from the MODIS surface reflectance product and averaging the ground-measured effective LAIs that were located in the same one $500 \mathrm{~m}$ MODIS pixel, 88 pairs of MODIS surface-reflectance and ground measured effective LAI were obtained. The 88 pairs of ground LAIs were separated to two parts, 66 pairs for modeling and 22 pairs for validation. A good relationship was found between the effective LAI and NDVI $\mathrm{MODIS}_{\mathrm{S}}$ $\left(R^{2}\right.$ of 0.5036$)$ and between the effective LAI and $\mathrm{SR}_{\text {MODIS }}\left(R^{2}\right.$ of 0.5189 ) (Figure 6a). Considering the superior performance of $\mathrm{SR}_{\text {MODIS }}$ compared to that of $\mathrm{NDVI}_{\text {MODIS }}$, the LAI-SR $\mathrm{RODIS}_{\text {model was applied }}$ to the $500 \mathrm{~m}$ MODIS surface reflectance product to produce effective LAI maps. The 22 pairs of validation data also showed that the retrieved LAI maps had a good performance with RMSE of 
$0.2493 \mathrm{~m}^{2} / \mathrm{m}^{2}$ (Figure 6b). Because of the limitation of the sample size (total 88 pairs), the improvement to each scene of the LAI maps was not conducted here. However, the good performance of the derived LAI maps from Figure 6 indicated that theses maps were applicable to evaluate the MODIS LAI product.

Figure 6. Relationships between ground effective LAI and MODIS reflectance generated vegetation indices, and validation of retrieved LAI maps. (a) Relationships between ground

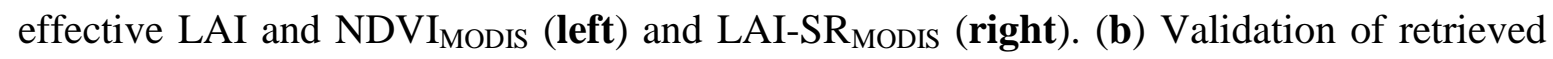
LAI maps derived from LAI-SR MODIS model.
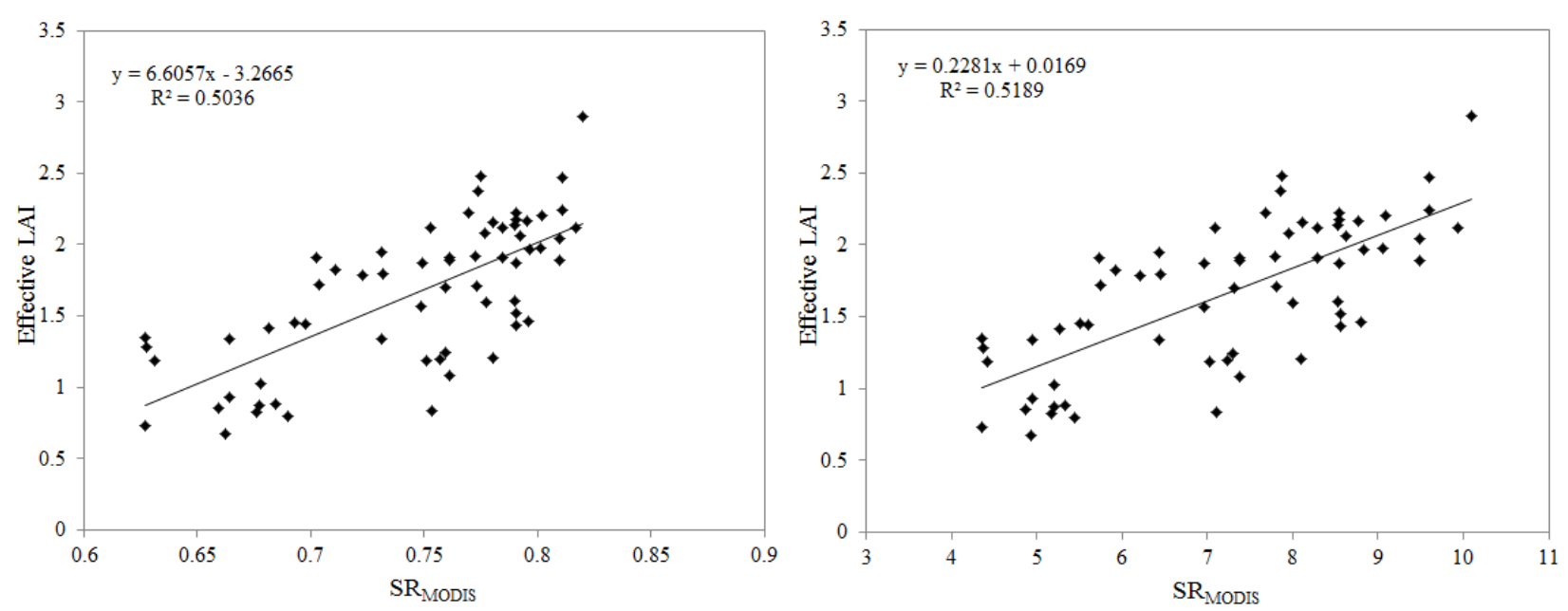

(a)

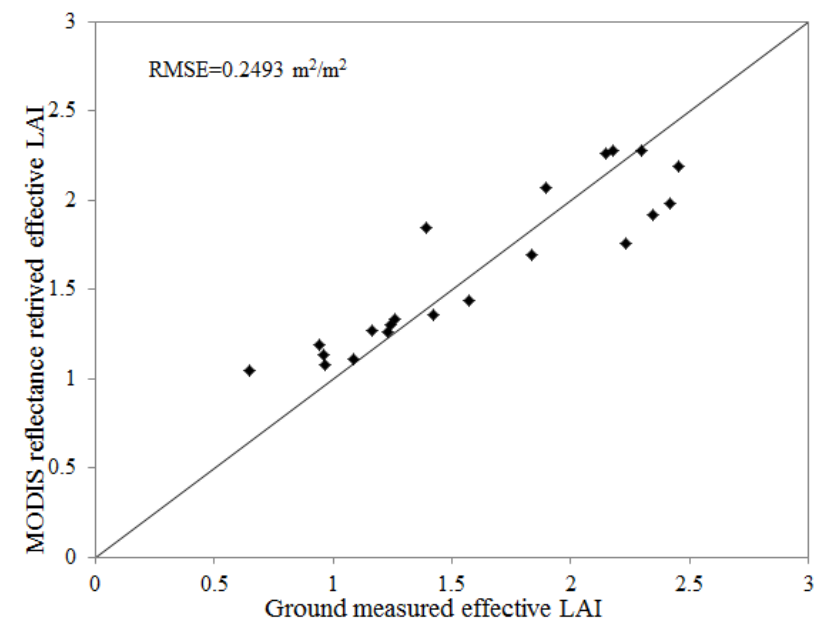

(b)

\section{Results and Discussion}

\subsection{Land Cover Comparison}

The land cover data influence the accuracy of the LAI products retrieval as this information is an important input of the MODIS LAI algorithms. The actual land cover of the study site is comprised entirely of grass and has an area of at least $10 \mathrm{~km} \times 10 \mathrm{~km}$. Our site was located at the center of this area. However, the land cover types interpreted from the MCD 12 Q1 product use the MODIS 12 land use classification (land cover type 3, LAI/fAPAR biomes), which showed an anomaly. The result is 
illustrated in Figure 7. Several pixels were misclassified, which shifted the classification from grass to broadleaf crops. Tan et al. [22] indicated that biome misclassification might have a two-fold effect: a direct effect, whereby the selection of an incorrect lookup table during the retrieval results from misclassification, and an indirect effect, which is reflected in the algorithm calibration procedure when the look up tables are developed. Myneni et al. [2] discussed the impact of land cover biome misclassification on the LAI value retrieval. They calculated that the LAI difference could be up to $70 \%$ when distinct biomes are interchanged. Pisek and Chen [45] reported that the effect of land cover misclassification on the MODIS LAI products varies depending on the similarity between the biomes. Myneni et al. [2] calculated a 15\% LAI overestimation for the misclassification of grass to broadleaf crops, but they also stressed that it is difficult to quantitatively assess the uncertainty due to the spectral and structural similarities between the two biomes.

Figure 7. The land cover map of the study site.

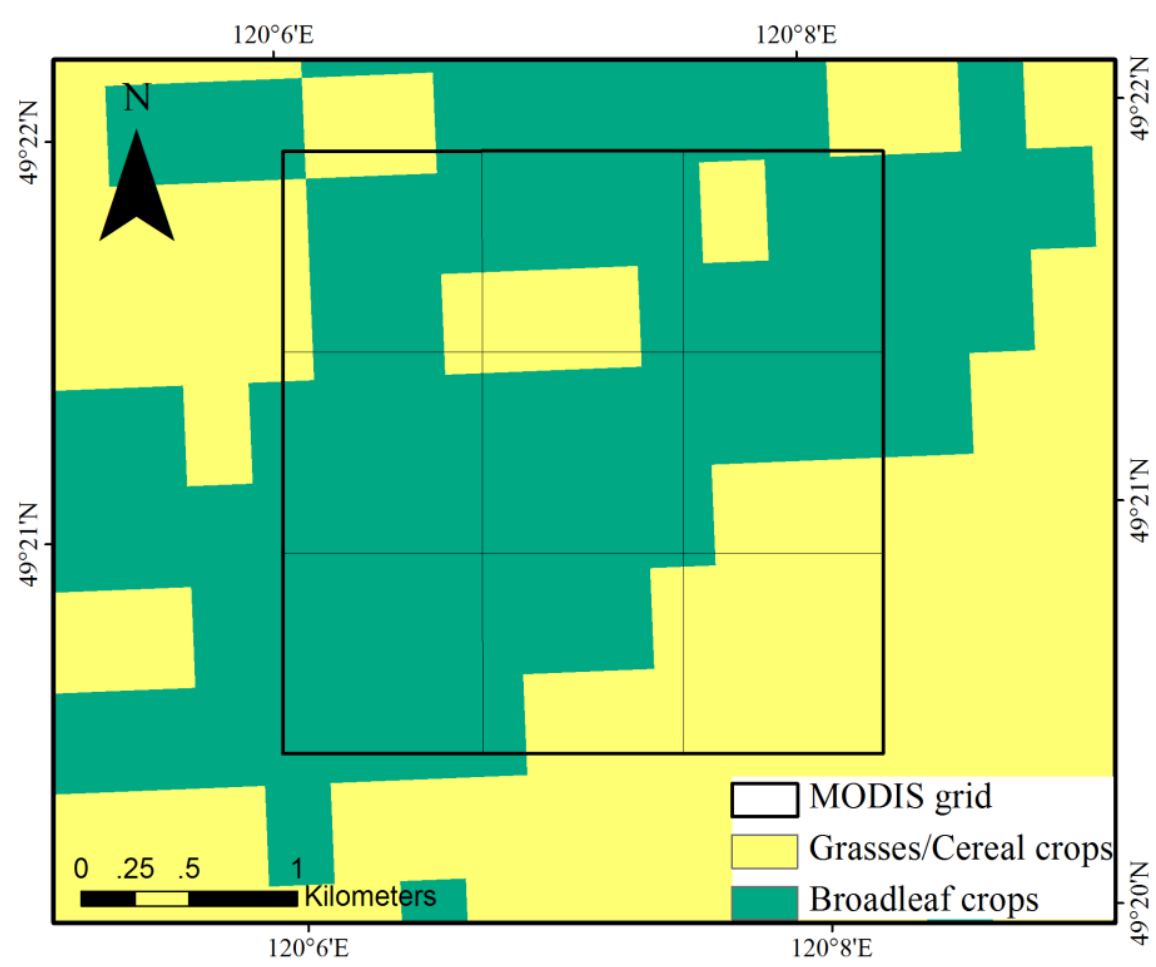

\subsection{Comparison between HJ Retrieved LAI and the MODIS LAI Product}

\subsubsection{Pixel-by-Pixel Comparison}

After the effective LAI maps of seven scenes during the growing season were obtained, the LAI maps were calculated using Equation (1) with an empirical clumping index value of 0.9. Then, the reference $1 \mathrm{~km}$ LAI maps were aggregated from the $30 \mathrm{~m} \mathrm{HJ}$ pixels via averaging to match the corresponding low-resolution pixels of the MODIS. Although pixel-by-pixel comparisons were not recommended in many previous MODIS LAI validation research studies due to geolocational uncertainties, pixel-shift errors, and algorithm uncertainties [10,29,46,48], the homogeneous surface and large validation dataset in this study could partly reduce these effects. Using nine pixels over the study site (Figure 1), the scatterplot for the pixel-by-pixel comparisons of the LAI products is shown in 
Figure 8. Good agreement was achieved with an $R^{2}$ of 0.6851 and RMSE of $0.5373 \mathrm{~m}^{2} / \mathrm{m}^{2}$. However, the overestimation of the LAI by the MODIS product is obvious compared to the HJ-retrieved LAI maps, even not so great. The average LAI overestimation was $0.47 \mathrm{~m}^{2} / \mathrm{m}^{2}$ for all pixels, and the average relative absolute error was $30.17 \%$ during the growing season. Moreover, smaller LAI values result in greater overestimation by the MODIS LAI products (Figure 8, right). This is likely because in this study site, pixels with larger LAI values tend to be comprised of homogeneous stands.

Figure 8. Pixel-by-pixel correlation between the MODIS and aggregated HJ LAI values (left) and the scatter-plot of the average relative absolute error with HJ LAI values (right).
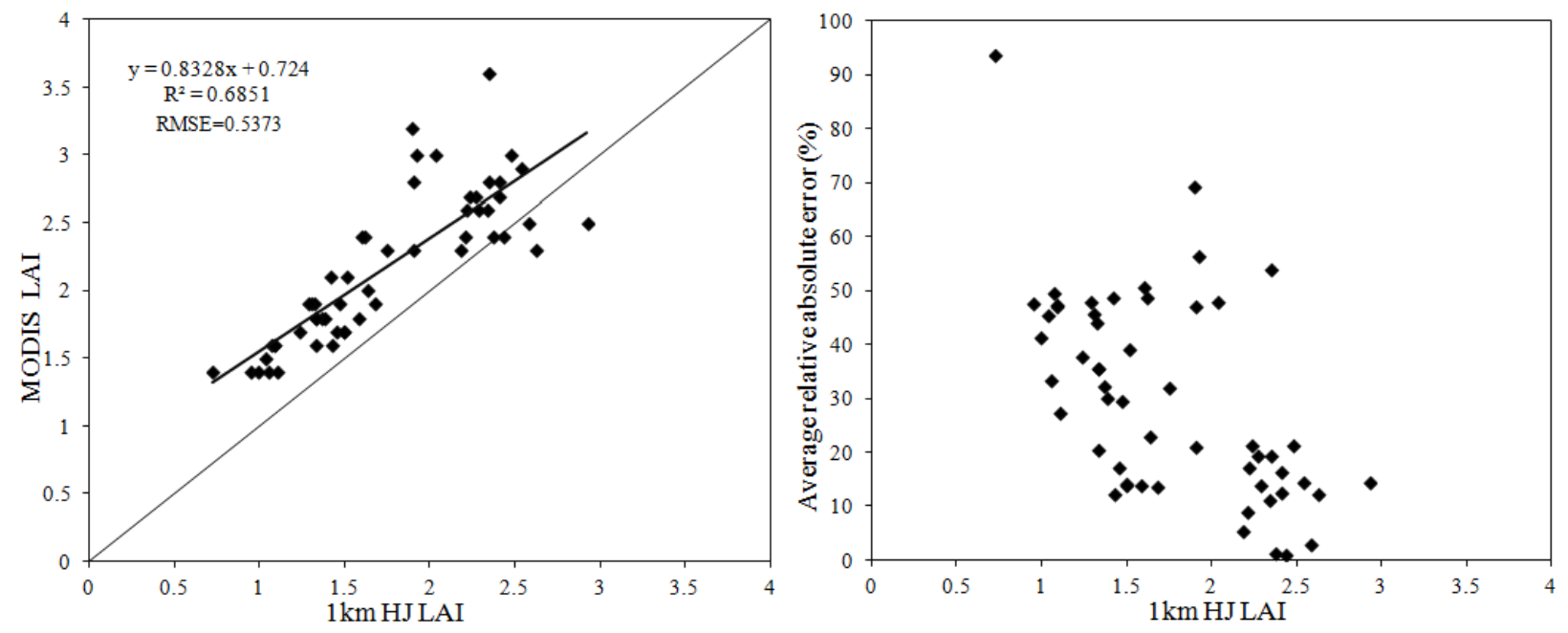

\subsubsection{Patch-by-Patch Comparison}

Generally, it is more reasonable to perform comparisons on the patch scale to minimize the uncertainties in the inputs and the algorithm of the pixel comparison [28]. The pasture in the site was comprised of three types: cutting pasture, grazing pasture, and enclosed pasture. Considering the small area of enclosed pasture $(600 \mathrm{~m} \times 600 \mathrm{~m})$, which was smaller than one pixel in the image, the patch-by-patch comparisons were conducted at the scales of the entire site, the cutting pasture, and the grazing pasture. The LAI of the entire site was calculated by averaging the nine pixels of the site. The cutting pasture LAI was calculated by averaging the four upper-left pixels, and the grazing pasture LAI was calculated by averaging the four lower-right pixels. The results are illustrated in Figure 9 and Table 3. A better agreement was achieved at the patch scale in which the $R^{2}$ is 0.73 for the entire site, but a slight overestimation occurred for the MODIS LAI products during the growing season compared to the HJ-retrieved LAI maps (the upper-left graph of Figure 9). Good agreement was also observed between the ground measured LAIs (after applying the clumping index) and the $1 \mathrm{~km} \mathrm{HJ}$ LAIs on most dates, except for 19 August (day 233), which may be caused by the unrepresentative sample points due to the grass-cutting activity.

For the entire site (the upper right graph of Figure 9), the MODIS products correlated reasonably well with the aggregated HJ LAI maps $\left(R^{2}\right.$ of 0.86$)$. The average relative absolute error was $27.77 \%$ (Table 3). However, an anomaly occurred at the beginning of the growing season. The MODIS LAI value increased sharply from $1.48 \mathrm{~m}^{2} / \mathrm{m}^{2}$ on 4 June (day 162) to $2.50 \mathrm{~m}^{2} / \mathrm{m}^{2}$ on 23 June (day 178), and remained steady, whereas the aggregated HJ LAI exhibited a stable increase until 13 July (day 194). 
Overall, the average overestimation of the LAI was approximately $0.43 \mathrm{~m}^{2} / \mathrm{m}^{2}$ for the MODIS product $\left(\mathrm{RMSE}=0.49 \mathrm{~m}^{2} / \mathrm{m}^{2}\right.$ ) and was lower than an LAI value of 1 during the growing season. Moreover, the overestimation was higher at the beginning and end of the growing season than at the peak. This pattern was due to an increased amount of radiation reflected from the background as the satellite image pixels aggregated to a lower spatial resolution [49]. As soil interference increases, the magnitude of the underestimation also increases [50].

Figure 9. Patch-by-patch comparison between the MODIS and the aggregated HJ LAI values. The error bars indicate the standard deviations. (a) The scatter-plot of patch-by-patch comparison; (b) The entire site comparison; (c) Cutting pasture comparison; (d) Grazing pasture comparison.

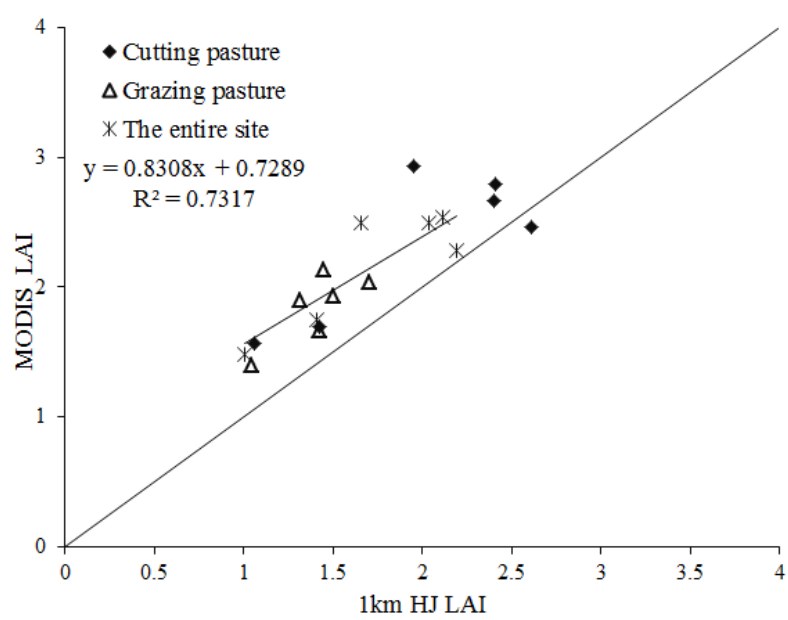

(a)

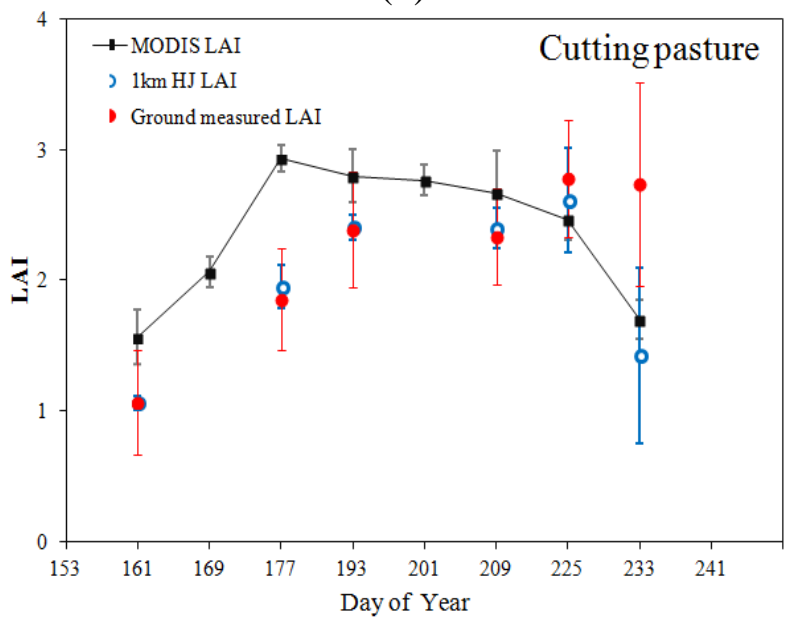

(c)

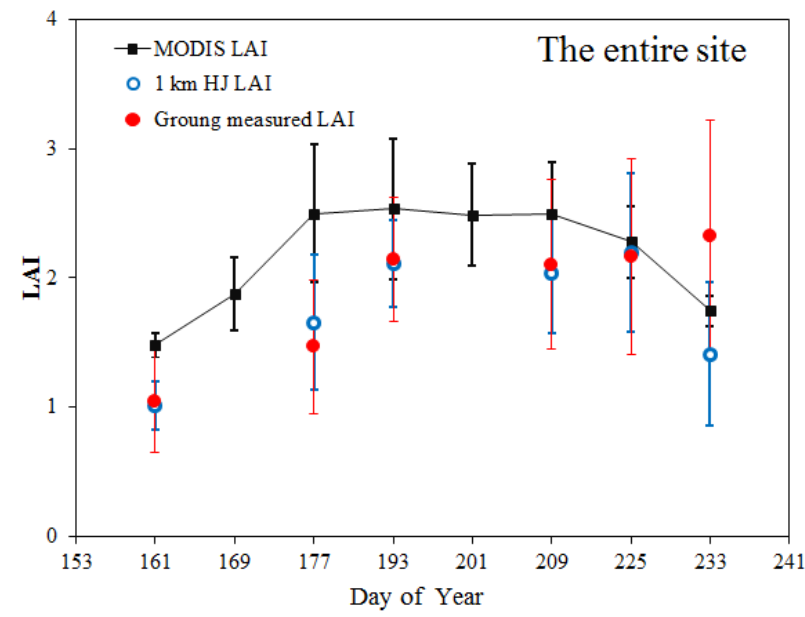

(b)

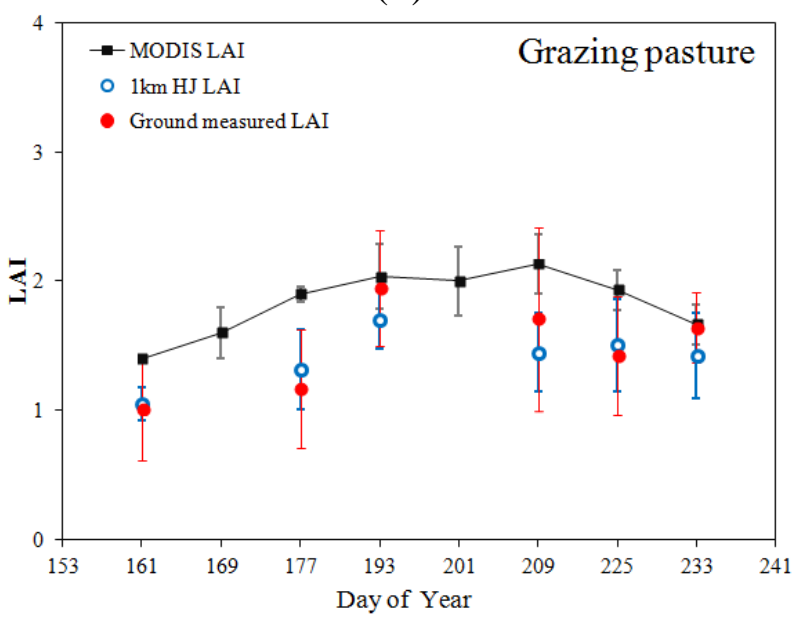

(d)

In the cutting pasture, the grass was enclosed by a fence to prevent grazing by cattle until late August every year. Then, the grass was cut at the optimum time for silage production. The performance of the MODIS LAI product in this pasture was better than that of the entire site compared to the HJ-retrieved LAI maps; a good seasonal trajectory followed the growing season, and a smaller overestimation during the peak of the growing season was observed. The correlation coefficient between the MODIS and the aggregated HJ LAI was 0.81, and the average relative absolute error was $23.36 \%$, which is smaller than that of the entire site. The highest LAI value of the MODIS product, 
$2.93 \mathrm{~m}^{2} / \mathrm{m}^{2}$, occurred on 23 June (day 178), which increased sharply from $1.57 \mathrm{~m}^{2} / \mathrm{m}^{2}$ on 4 June (day 162) and then remained steady. For the aggregated HJ LAI, a stable increase in the LAI resulted in a peak around 11 August, which was followed by a sharp decrease on 19 August (day 234) due to the cutting activity. The stable stage of the LAI value occurred between 23 June (day 178) and 21 July (day 213) for the MODIS data and between 6 July (day 186) and 11 August (day 226) for the aggregated HJ LAI. Yang et al. [51] showed that an anomalous seasonality occurred over small regions using the simulated Terra and the Aqua MODIS LAI C5 products. The anomalous seasonality was caused by the scattering effect of aerosol contamination on surface reflectances during the growing season. They also reported that the limitations of the radiative transfer algorithm with respect to the solar zenith angle affect model of the seasonal variations of the MODIS surface reflectance data. In this study, another reason may be due to the fast growth or variation of the grass at the beginning and end of the growing season, which led to a large variation of the surface reflectance during the MODIS LAI product composite intervals; thus, the input surface reflectances of the product algorithm were impacted, which was also reported in the previous collections, C3 and C4 [22,45]. The mean overestimation of the LAI in this pasture was approximately $0.43 \mathrm{~m}^{2} / \mathrm{m}^{2}$ for the MODIS product $\left(\mathrm{RMSE}=0.51 \mathrm{~m}^{2} / \mathrm{m}^{2}\right.$ ).

Table 3. Statistics of patch-by-patch comparison between the MODIS and aggregated HJ LAI values.

\begin{tabular}{|c|c|c|c|c|c|c|c|c|c|c|}
\hline Patch & $\begin{array}{c}\text { Mean LAI } \\
\text { Value }\left(\mathrm{m}^{2} / \mathbf{m}^{2}\right)\end{array}$ & $\begin{array}{c}\text { 4 June } \\
(161) \\
\end{array}$ & $\begin{array}{c}23 \text { June } \\
(177) \\
\end{array}$ & $\begin{array}{c}\text { 13 July } \\
(193)\end{array}$ & $\begin{array}{c}25 \text { July } \\
(209) \\
\end{array}$ & $\begin{array}{c}11 \text { August } \\
(225)\end{array}$ & $\begin{array}{c}19 \text { August } \\
(233)\end{array}$ & $\begin{array}{c}\text { Average } \\
\text { Relative Error }\end{array}$ & $R^{2}$ & $\begin{array}{l}\text { RMSE } \\
\left(\mathbf{m}^{2} / \mathbf{m}^{2}\right) \\
\end{array}$ \\
\hline \multirow{3}{*}{$\begin{array}{c}\text { The entire } \\
\text { site }\end{array}$} & $1 \mathrm{~km} \mathrm{HJ}$ & 1.01 & 1.66 & 2.11 & 2.04 & 2.20 & 1.41 & & & \\
\hline & MODIS & 1.48 & 2.50 & 2.53 & 2.50 & 2.28 & 1.74 & & & \\
\hline & relative error & 46.53 & 50.60 & 19.91 & 22.55 & 3.64 & 23.40 & 27.77 & 0.86 & 0.49 \\
\hline \multirow{3}{*}{$\begin{array}{l}\text { Cutting } \\
\text { pasture }\end{array}$} & $1 \mathrm{~km} \mathrm{HJ}$ & 1.06 & 1.95 & 2.41 & 2.40 & 2.61 & 1.42 & & & \\
\hline & MODIS & 1.57 & 2.93 & 2.80 & 2.67 & 2.47 & 1.70 & & & \\
\hline & relative error & 48.11 & 50.26 & 16.18 & 11.25 & -5.36 & 19.72 & 23.36 & 0.81 & 0.51 \\
\hline \multirow{3}{*}{$\begin{array}{l}\text { Grazing } \\
\text { pasture }\end{array}$} & $1 \mathrm{~km} \mathrm{HJ}$ & 1.05 & 1.32 & 1.70 & 1.45 & 1.51 & 1.42 & & & \\
\hline & MODIS & 1.40 & 1.90 & 2.03 & 2.13 & 1.93 & 1.67 & & & \\
\hline & relative error & 33.33 & 43.94 & 19.41 & 46.90 & 27.81 & 17.61 & 31.50 & 0.78 & 0.46 \\
\hline
\end{tabular}

In the grazing pasture, the grass was eaten by cattle during the entire growing season. A stable LAI value of $1.5 \mathrm{~m}^{2} / \mathrm{m}^{2}$ was maintained during the peak of the growing season, and the MODIS performed well, with an LAI value of $2 \mathrm{~m}^{2} / \mathrm{m}^{2}$. The LAI overestimate was higher for the grazing pasture than for the cutting pasture during the peak of the growing season due to the additional background interference. The mean overestimated LAI of this pasture was approximately $0.44 \mathrm{~m}^{2} / \mathrm{m}^{2}$ for the MODIS product, and the average relative absolute error was $31.50 \%\left(\mathrm{RMSE}=0.46 \mathrm{~m}^{2} / \mathrm{m}^{2}\right.$ ).

\subsection{Comparison between the $500 \mathrm{~m}$ MODIS Reflectance Retrieved LAI and the MODIS LAI Product}

The $500 \mathrm{~m}$ MODIS reflectance retrieved LAI maps derived in this study may have more uncertainties than the HJ retrieved LAI maps due to the relatively small sample size in one $500 \mathrm{~m}$ MODIS reflectance pixel, which would introduce more "noise" into the regression model development. However, this comparison was still necessary because it could provide a direct estimation of the LP DAAC MODIS LAI product and provide support for the findings using the HJ LAI product and the 
ground-based comparison originally suggested. Moreover, the well-performing LAI-NDVI MODIS $_{\text {model }}$ also indicated that the site had a small spatial variability and relatively homogeneous surface, which would partially reduce the impact of the small sample size.

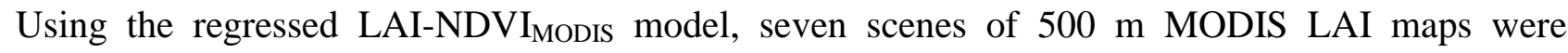
obtained after eliminating the clumping effect using Equation (1). Then, the $500 \mathrm{~m}$ MODIS LAI pixels were aggregated to produce the $1 \mathrm{~km}$ LAI (named the aggregated $1 \mathrm{~km}$ MODIS LAI) maps via averaging to match the corresponding low-resolution pixels of the MODIS. The comparison was also conducted at the pixel and patch scales (the entire site) (Figure 10). From Figure 10, a slight overestimation of the LP DAAC MODIS LAI product was observed compared to the aggregated $1 \mathrm{~km}$ MODIS LAI maps derived in this study, which was consistent with the results using the HJ-retrieved LAI maps. The average bias was $0.43 \mathrm{~m}^{2} / \mathrm{m}^{2}$ for the pixel comparison (RMSE $=0.5357 \mathrm{~m}^{2} / \mathrm{m}^{2}$ ) and $0.44 \mathrm{~m}^{2} / \mathrm{m}^{2}$ for the patch comparison $\left(\mathrm{RMSE}=0.5147 \mathrm{~m}^{2} / \mathrm{m}^{2}\right.$ ) during the growing season.

Figure 10. Comparison between the LP DAAC MODIS LAI and the aggregated $1 \mathrm{~km}$ MODIS reflectance retrieved LAI values at the pixel (left) and patch (right) scale. The error bars indicate the standard deviations.
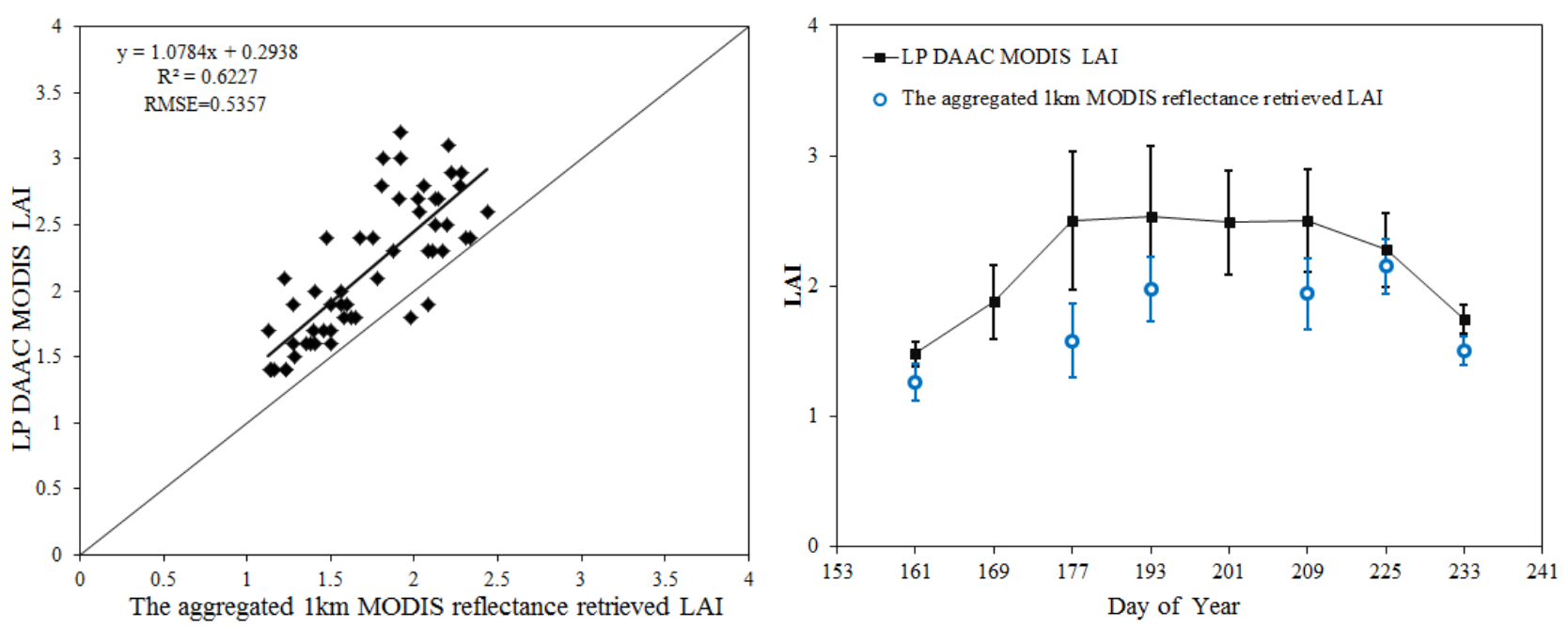

\subsection{Consideration of Sources of Error and Uncertainty}

Yang et al. [10] suggested three key factors that influence the accuracy of the MODIS LAI retrievals: the uncertainties in the input land cover data [47]; the uncertainties in the input surface reflectances [16,22]; and the uncertainties in the model used to build the look-up tables that accompany the algorithm [22,52]. Tian et al. [29] also detected that a 5\% underestimation of the LAI values would be obtained if the scale of the MODIS algorithm is not matched to the resolution of the data. Considering the actual conditions of this study, the misclassification of land cover was assumed to have little effect on the MODIS retrieved LAI due to the similar structures of grass and crops as noted by Myneni et al. [2]. In terms of the uncertainties in the input surface reflectances, vegetation structural heterogeneity may considerably influence the radiative signals at different spatial resolutions, especially when coarse-resolution pixels consist of various land cover types [53]. In our site, the land cover is comprised entirely of grass, but differences still exist for the grass growth periods. During the peak of the growing season, the grass almost entirely covered the ground, so the 
reflectance interference from the soil and understory was limited. However, at the beginning and end of the growing season, the ground conditions were more complex; the reflectance contributions from the soil and non-photosynthetic vegetation might have contributed to the reflectance products utilized in the MODIS LAI algorithms, which ultimately influenced the canopy LAI retrievals [54].

In terms of the uncertainty of the HJ-retrieved LAI maps, temporal discrepancies between the MODIS 8-day composite LAI product and LAI data acquisition campaigns may have affected the comparison results to some extent with respect to the applicability of our HJ-retrieved LAI maps to evaluate the MODIS LAI products, especially during the large variation of grass period (fast growth or withering) at the beginning and end of the growing season.

Understory vegetation and non-photosynthetic withered litters, which affect canopy variable (e.g., LAI, fPAR) estimation algorithms [55-57], were other factors that contributed to the discrepancies between the MODIS LAI and HJ-retrieved LAI. The error from the LAI measurements is higher later in the season because these measurements include more dead leaves. The MODIS LAI product was developed for estimating green or photosynthetically active leaf areas, while our regression models were developed for the canopy LAI that is measured by the LAI-2000 instrument. In this study, the percent of withered litter cover was not directly measured during the field campaign. Serbin et al. [58] evaluated spectral indices for the detection of crop residue/non-photosynthetic vegetation and recommended bands that could be used by Landsat and ASTER satellites. Ren and Zhou [59] estimated non-photosynthetic biomass in a desert steppe using the cellulose absorption index (CAI); they found models that involve the CAI yielded the highest coefficient of determination compared with other frequently used vegetation indices. They also reported the possibility of estimating senesced biomass using MODIS reflectance products. Spectral mixture analysis is also a well-established and effective technique to address the spectral mixture problem and calculate the percent of non-photosynthetic vegetation cover [60-64]. Further research could utilize these techniques to differentiate between withered litters versus photosynthetic vegetation contributions, which were not addressed in our study.

The error from the regression model was minimal and contributed little to the uncertainty because the HJ-retrieved LAI maps (RMSE $=0.34$ ) were improved using ground measured data from multiple field campaigns (Figure 5); even the empirical regression model does not seem as robust when using SR and NDVI. Errors in the field measurements of the LAI were also very important for obtaining the reference LAI maps [65], but little uncertainty from this factor was added to the analysis due to the homogeneous surface and normal distribution of the measured LAIs (Figure 3). Additionally, the atmospheric correction [66] and the aggregation method [67,68] may have a small influence on the generation of the reference map.

\section{Conclusions}

The assessment of satellite sensor derived products is necessary before accurate use of these products. This research assessed the accuracy of the MODIS LAI C5 product in a meadow steppe of Hulunber, Inner Mongolia, China using the ground measurements collected from seven field campaigns and seven scenes of corresponding HJ-1A/B CCD images during the growing season of 2013. Then, the accuracy of the MODIS LAI product was assessed by comparing it to the HJ-retrieved 
LAI maps at the pixel and patch scales. The $500 \mathrm{~m}$ MODIS LAI maps were also derived from the daily MODIS surface reflectance product to support the findings of HJ-retrieved LAI and the ground-based comparison. Moreover, the quality assessment datasets and land cover products were examined to assess the uncertainty in the product algorithm.

The results showed that a slight overestimation existed for the MODIS LAI products in the study site compared to the HJ-retrieved LAI maps. At the beginning and end of the growing season, the overestimation was greater due to the interference of the soil background and grass variation. The average overestimation of the LAI values was approximately 0.4 , which was within a 0.5 LAI accuracy and thus met the accuracy requirements for the LAI product, while the relative absolute errors in the growing season ranged from 10\%-50\%. Moreover, the seasonal trajectory of the MODIS LAI product was assessed, and a reasonable agreement was found following the growing season. However, an anomaly existed at the beginning of the growing season due to the uncertainty in the reflectance input and the algorithm [22,45,49], which might influence the accurate detection of the grassland phenological phase in this region. Therefore, a smoothing algorithm was needed to reconstruct the seasonal trajectories before the phenological analysis [69]. The results of this study provide a comprehensive understanding of the accuracy of the regional MODIS LAI product for the Hulunber meadow steppe, which is important for ecosystem modeling and prediction in this region.

However, the conclusions based on the above analysis are particular to the grassland biome of the study area used. Future studies should consider more land cover biomes, and longer-term assessment and intercomparison with other leaf area index products should be conducted.

\section{Acknowledgments}

We gratefully acknowledge the financial support provided from the International Science and Technology Cooperation Project of China (2012DFA31290) and the Key Technologies Research and Development Program of China (2013BAC03B02, 2012BAC19B04). We also acknowledge the USGS and China Centre for Resources Satellite Data and Application for providing the MODIS and HJ-1A/B CCD data.

\section{Author Contributions}

All authors made great contributions to the work. Zhenwang Li and Huan Tang performed the analyses and prepared the paper. Xiaoping Xin provided the technical guidance and contributed to the discussion. Huan Tang, Baohui Zhang and Dongliang Wang helped field data collection and image analysis.

\section{Conflicts of Interest}

The authors declare no conflict of interest.

\section{References}

1. Chen, J.M.; Black, T. Defining leaf area index for non-flat leaves. Plant Cell Environ. 1992, 15, $421-429$. 
2. Myneni, R.; Hoffman, S.; Knyazikhin, Y.; Privette, J.; Glassy, J.; Tian, Y.; Wang, Y.; Song, X.; Zhang, Y.; Smith, G. Global products of vegetation leaf area and fraction absorbed PAR from year one of MODIS data. Remote Sens. Environ. 2002, 83, 214-231.

3. Running, S.W.; Nemani, R.R.; Peterson, D.L.; Band, L.E.; Potts, D.F.; Pierce, L.L.; Spanner, M.A. Mapping regional forest evapotranspiration and photosynthesis by coupling satellite data with ecosystem simulation. Ecology 1989, 70, 1090-1101.

4. Sellers, P.; Dickinson, R.; Randall, D.; Betts, A.; Hall, F.; Berry, J.; Collatz, G.; Denning, A.; Mooney, H.; Nobre, C. Modeling the exchanges of energy, water, and carbon between continents and the atmosphere. Science 1997, 275, 502-509.

5. Bonan, G.B. Land-atmosphere interactions for climate system models: Coupling biophysical, biogeochemical, and ecosystem dynamical processes. Remote Sens. Environ. 1995, 51, 57-73.

6. Foley, J.A.; Levis, S.; Prentice, I.C.; Pollard, D.; Thompson, S.L. Coupling dynamic models of climate and vegetation. Glob. Chang. Biol. 1998, 4, 561-579.

7. Justice, C.O.; Vermote, E.; Townshend, J.R.; Defries, R.; Roy, D.P.; Hall, D.K.; Salomonson, V.V.; Privette, J.L.; Riggs, G.; Strahler, A. The Moderate Resolution Imaging Spectroradiometer (MODIS): Land remote sensing for global change research. IEEE Trans. Geosci. Remote Sens. 1998, 36, 1228-1249.

8. Privette, J.; Asner, G.; Conel, J.; Huemmrich, K.; Olson, R.; Rango, A.; Rahman, A.; Thome, K.; Walter-Shea, E.A. The EOS prototype validation exercise (PROVE) at Jornada: Overview and lessons learned. Remote Sens. Environ. 2000, 74, 1-12.

9. Privette, J.; Myneni, R.; Knyazikhin, Y.; Mukelabai, M.; Roberts, G.; Tian, Y.; Wang, Y.; Leblanc, S. Early spatial and temporal validation of MODIS LAI product in the Southern Africa Kalahari. Remote Sens. Environ. 2002, 83, 232-243.

10. Yang, W.; Tan, B.; Huang, D.; Rautiainen, M.; Shabanov, N.V.; Wang, Y.; Privette, J.L.; Huemmrich, K.F.; Fensholt, R.; Sandholt, I. MODIS leaf area index products: From validation to algorithm improvement. IEEE Trans. Geosci. Remote Sens. 2006, 44, 1885-1898.

11. Morisette, J.T.; Privette, J.L.; Justice, C.O. A framework for the validation of MODIS land products. Remote Sens. Environ. 2002, 83, 77-96.

12. Justice, C.; Belward, A.; Morisette, J.; Lewis, P.; Privette, J.; Baret, F. Developments in the "validation" of satellite sensor products for the study of the land surface. Int. J. Remote Sens. 2000, 21, 3383-3390.

13. Gessner, U.; Niklaus, M.; Kuenzer, C.; Dech, S. Intercomparison of leaf area index products for a gradient of sub-humid to arid environments in West Africa. Remote Sens. 2013, 5, 1235-1257.

14. Linking In Situ Measurements, Remote Sensing, and Models to Validate MODIS Products Related to the Terrestrial Carbon Cycle. Available online: http://www.fsl.orst.edu/larse/bigfoot/index.html (accessed on 18 May 2013).

15. Morisette, J.T.; Baret, F.; Privette, J.L.; Myneni, R.B.; Nickeson, J.E.; Garrigues, S.; Shabanov, N.V.; Weiss, M.; Fernandes, R.A.; Leblanc, S.G. Validation of global moderate-resolution LAI products: A framework proposed within the CEOS land product validation subgroup. IEEE Trans. Geosci. Remote Sens. 2006, 44, 1804-1817. 
16. Cohen, W.B.; Maiersperger, T.K.; Yang, Z.; Gower, S.T.; Turner, D.P.; Ritts, W.D.; Berterretche, M.; Running, S.W. Comparisons of land cover and LAI estimates derived from ETM+ and MODIS for four sites in North America: A quality assessment of 2000/2001 provisional MODIS products. Remote Sens. Environ. 2003, 88, 233-255.

17. Cohen, W.B.; Maiersperger, T.K.; Turner, D.P.; Ritts, W.D.; Pflugmacher, D.; Kennedy, R.E.; Kirschbaum, A.; Running, S.W.; Costa, M.; Gower, S.T. MODIS land cover and LAI collection 4 product quality across nine sites in the western hemisphere. IEEE Trans. Geosci. Remote Sens. 2006, 44, 1843-1857.

18. VAlidation of Land European Remote Sensing Instruments. Available online: http://w3.avignon. inra.fr/valeri/ (accessed on 18 May 2013).

19. VALERI: A Network of Sites and a Methodology for the Validation of Medium Spatial Resolution Land Satellite Products. Available online: http://w3.avignon.inra.fr/valeri/documents/ VALERI-RSESubmitted.pdf (accessed on 18 May 2013).

20. CEOS Committee on Earth Observation Satellites. Available online: http://www.ceos.org/ (accessed on 18 May 2013).

21. De Kauwe, M.; Disney, M.; Quaife, T.; Lewis, P.; Williams, M. An assessment of the MODIS collection 5 leaf area index product for a region of mixed coniferous forest. Remote Sens. Environ. 2011, 115, 767-780.

22. Tan, B.; Hu, J.; Huang, D.; Yang, W.; Zhang, P.; Shabanov, N.V.; Knyazikhin, Y.; Nemani, R.R.; Myneni, R.B. Assessment of the broadleaf crops leaf area index product from the Terra MODIS instrument. Agric. For. Meteorol. 2005, 135, 124-134.

23. Shabanov, N.; Samata, A.; Myneni, R.; Knyazikhin, Y.; Votava, P. Collection 5 MODIS LAI and FPAR Products; MODIS STM, University of Maryland: College Park, MD, USA, 2007.

24. Friedl, M.A.; Sulla-Menashe, D.; Tan, B.; Schneider, A.; Ramankutty, N.; Sibley, A.; Huang, X. MODIS collection 5 global land cover: Algorithm refinements and characterization of new datasets. Remote Sens. Environ. 2010, 114, 168-182.

25. Chen, J.M.; Pavlic, G.; Brown, L.; Cihlar, J.; Leblanc, S.; White, H.; Hall, R.; Peddle, D.; King, D.; Trofymow, J. Derivation and validation of Canada-wide coarse-resolution leaf area index maps using high-resolution satellite imagery and ground measurements. Remote Sens. Environ. 2002, 80, 165-184.

26. Tian, Y.; Woodcock, C.E.; Wang, Y.; Privette, J.L.; Shabanov, N.V.; Zhou, L.; Zhang, Y.; Buermann, W.; Dong, J.; Veikkanen, B. Multiscale analysis and validation of the MODIS LAI product: II. Sampling strategy. Remote Sens. Environ. 2002, 83, 431-441.

27. Weiss, M.; de Beaufort, L.; Baret, F.; Allard, D.; Bruguier, N.; Marloie, O. Mapping Leaf Area Index Measurements at Different Scales for the Validation of Large Swath Satellite Sensors: First Results of the VALERI Project. In Proceedings of the 8th International Symposium on Physical Measurements and Signatures in Remote Sensing, Aussois, France, 2001; pp. 125-130.

28. Wang, Y.; Woodcock, C.E.; Buermann, W.; Stenberg, P.; Voipio, P.; Smolander, H.; Häme, T.; Tian, Y.; Hu, J.; Knyazikhin, Y. Evaluation of the MODIS LAI algorithm at a coniferous forest site in Finland. Remote Sens. Environ. 2004, 91, 114-127. 
29. Tian, Y.; Woodcock, C.E.; Wang, Y.; Privette, J.L.; Shabanov, N.V.; Zhou, L.; Zhang, Y.; Buermann, W.; Dong, J.; Veikkanen, B. Multiscale analysis and validation of the MODIS LAI product: I. Uncertainty assessment. Remote Sens. Environ. 2002, 83, 414-430.

30. Wu, H.; Li, Z.-L. Scale issues in remote sensing: A review on analysis, processing and modeling. Sensors 2009, 9, 1768-1793.

31. Ma, M.; Li, X.; Wang, W.; Xiao, Q.; Zhao, K.; Xin, X. Design on Validation Network of Remote Sensing Products in China. In Proceedings of the 8th International Symposium on Spatial Data Quality, Hong Kong, China, 30 May-1 June 2013; Volume XL-2/W1.

32. Yan, Y.; Xin, X.; Xu, X.; Wang, X.; Yang, G.; Yan, R.; Chen, B. Quantitative effects of wind erosion on the soil texture and soil nutrients under different vegetation coverage in a semiarid steppe of northern China. Plant Soil 2013, 369, 585-598.

33. Welles, J.M.; Norman, J.M. Instrument for indirect measurement of canopy architecture. Agron. J. 1991, 83, 818-825.

34. Huemmrich, K.F.; Privette, J.L.; Mukelabai, M.; Myneni, R.B.; Knyazikhin, Y. Time-series validation of MODIS land biophysical products in a Kalahari woodland, Africa. Int. J. Remote Sens. 2005, 26, 4381-4398.

35. Chen, J.M.; Cihlar, J. Retrieving leaf area index of boreal conifer forests using Landsat TM images. Remote Sens. Environ. 1996, 55, 153-162.

36. Knyazikhin, Y.; Glassy, J.; Privette, J.; Tian, Y.; Lotsch, A.; Zhang, Y.; Wang, Y.; Morisette, J.; Votava, P.; Myneni, R. MODIS Leaf Area Index (LAI) and Fraction of Photosynthetically Active Radiation Absorbed by Vegetation (FPAR) Product (MOD15); Algorithm Theoretical Basis Document; NASA Goddard Space Flight Center: Greenbelt, MD, USA, 1999.

37. Liu, R.; Chen, J.M.; Liu, J.; Deng, F.; Sun, R. Application of a new leaf area index algorithm to China's landmass using MODIS data for carbon cycle research. J. Environ. Manag. 2007, 85, 649-658.

38. China Centre for Resources Satellite Data and Application. Available online: http://www.cresda. com/n16/n92006/index.html (accessed on 18 May 2013).

39. Wang, Q.; Wu, C.; Li, Q.; Li, J. Chinese HJ-1A/B satellites and data characteristics. Sci. China Earth Sci. 2010, 53, 51-57.

40. Sun, L.; Sun, C.; Liu, Q.; Zhong, B. Aerosol optical depth retrieval by HJ-1/CCD supported by MODIS surface reflectance data. Sci. China Earth Sci. 2010, 53, 74-80.

41. Agrawal, G.; Bhopal, M.; Sarup, J. Comparision of QUAC and FLASSH atmospheric correction modules on EO-1 hyperion data of Sanchi. Int. J. Adv. Eng. Sci. Technol. 2011, 4, 178-186.

42. He, L.; Wang, H.; Yan, G.; Li, X.; Zhu, W.; Wang, J. Analysis and application for the empirical relative between aerosol optical depth and horizontal meteorological range. J. Remote Sens. 2003, 7, 372-378. (In Chinese)

43. LP DAAC: NASA Land Data Products and Servaces. Available online: https://lpdaac.usgs.gov/ (accessed on 18 May 2013).

44. Myneni, R.; Knyazikhin, Y.; Glassy, J.; Votava, P.; Shabanov, N. User's Guide: FPAR, LAI (ESDT: MOD15A2) 8-Day Composite NASA MODIS Land Algorithm; Boston University: Boston, MA, USA, 2003. 
45. Pisek, J.; Chen, J.M. Comparison and validation of MODIS and VEGETATION global LAI products over four BigFoot sites in North America. Remote Sens. Environ. 2007, 109, 81-94.

46. Wang, Y.; Tian, Y.; Zhang, Y.; El-Saleous, N.; Knyazikhin, Y.; Vermote, E.; Myneni, R.B. Investigation of product accuracy as a function of input and model uncertainties: Case study with SEAWiFS and MODIS LAI/FPAR algorithm. Remote Sens. Environ. 2001, 78, 299-313.

47. Tan, B.; Hu, J.; Zhang, P.; Huang, D.; Shabanov, N.; Weiss, M.; Knyazikhin, Y.; Myneni, R.B. Validation of Moderate Resolution Imaging Spectroradiometer leaf area index product in croplands of Alpilles, France. J. Geophys. Res. 2005, 110, doi:10.1029/2004JD004860.

48. Knyazikhin, Y.; Martonchik, J.; Diner, D.; Myneni, R.; Verstraete, M.; Pinty, B.; Gobron, N. Estimation of vegetation canopy leaf area index and fraction of absorbed photosynthetically active radiation from atmosphere-corrected MISR data. J. Geophys. Res. 1998, 103, 32239-32256.

49. Tian, Y.; Zhang, Y.; Knyazikhin, Y.; Myneni, R.B.; Glassy, J.M.; Dedieu, G.; Running, S.W. Prototyping of MODIS LAI and FPAR algorithm with LASUR and LANDSAT data. IEEE Trans. Geosci. Remote Sens. 2000, 38, 2387-2401.

50. Fensholt, R.; Sandholt, I.; Rasmussen, M.S. Evaluation of MODIS LAI, fAPAR and the relation between fAPAR and NDVI in a semi-arid environment using in situ measurements. Remote Sens. Environ. 2004, 91, 490-507.

51. Yang, W.; Shabanov, N.; Huang, D.; Wang, W.; Dickinson, R.; Nemani, R.; Knyazikhin, Y.; Myneni, R. Analysis of leaf area index products from combination of MODIS Terra and Aqua data. Remote Sens. Environ. 2006, 104, 297-312.

52. Knyazikhin, Y.; Martonchik, J.V.; Myneni, R.B.; Diner, D.J.; Running, S.W. Synergistic algorithm for estimating vegetation canopy leaf area index and fraction of absorbed photosynthetically active radiation from MODIS and MISR data. J. Geophys. Res. 1998, 103, 32257-32275.

53. Jin, Z.; Tian, Q.; Chen, J.M.; Chen, M. Spatial scaling between leaf area index maps of different resolutions. J. Environ. Manag. 2007, 85, 628-637.

54. Jensen, J.L.R.; Humes, K.S.; Hudak, A.T.; Vierling, L.A.; Delmelle, E. Evaluation of the MODIS LAI product using independent lidar-derived LAI: A case study in mixed conifer forest. Remote Sens. Environ. 2011, 115, 3625-3639.

55. Eriksson, H.M.; Eklundh, L.; Kuusk, A.; Nilson, T. Impact of understory vegetation on forest canopy reflectance and remotely sensed LAI estimates. Remote Sens. Environ. 2006, 103, 408-418.

56. Steinberg, D.C.; Goetz, S.J.; Hyer, E.J. Validation of MODIS F/sub PAR/products in boreal forests of Alaska. IEEE Trans. Geosci. Remote Sens. 2006, 44, 1818-1828.

57. Chasmer, L.; Hopkinson, C.; Treitz, P.; McCaughey, H.; Barr, A.; Black, A. A lidar-based hierarchical approach for assessing MODIS fPAR. Remote Sens. Environ. 2008, 112, 4344-4357.

58. Serbin, G.; Daughtry, C.S.; Hunt, E.R., Jr.; McCarty, G.W.; Doraiswamy, P.C. Remote Sensing of Crop Residue and Non-Photosynthetic Vegetation. In Proceedings of the 2008 NASA Carbon Cycle and Ecosystems Joint Science Workshop, Adelphi, MD, USA, 28 April-2 May 2008; pp. 222-224.

59. Ren, H.; Zhou, G. Estimating senesced biomass of desert steppe in Inner Mongolia using field spectrometric data. Agric. For. Meteorol. 2012, 161, 66-71. 
60. Guan, H.; Xie, H.; Zhu, M. Canopy blockage and scattering effects on apparent soil spectral reflectance and its consequence in spectral mixture analysis of vegetated surfaces. Int. J. Remote Sens. 2008, 29, 3509-3522.

61. Powell, R.L.; Roberts, D.A.; Dennison, P.E.; Hess, L.L. Sub-pixel mapping of urban land cover using multiple endmember spectral mixture analysis: Manaus, Brazil. Remote Sens. Environ. 2007, 106, 253-267.

62. Lu, D.; Weng, Q. Spectral mixture analysis of the urban landscape in Indianapolis with Landsat ETM+ imagery. Photogramm. Eng. Remote Sens. 2004, 70, 1053-1062.

63. Somers, B.; Asner, G.P.; Tits, L.; Coppin, P. Endmember variability in spectral mixture analysis: A review. Remote Sens. Environ. 2011, 115, 1603-1616.

64. Guerschman, J.P.; Hill, M.J.; Renzullo, L.J.; Barrett, D.J.; Marks, A.S.; Botha, E.J. Estimating fractional cover of photosynthetic vegetation, non-photosynthetic vegetation and bare soil in the australian tropical savanna region upscaling the EO-1 hyperion and MODIS sensors. Remote Sens. Environ. 2009, 113, 928-945.

65. Dong, H.; Wenze, Y.; Tan, B.; Rautiainen, M.; Ping, Z.; Jiannan, H.; Shabanov, N.V.; Linder, S.; Knyazikhin, Y.; Myneni, R.B. The importance of measurement errors for deriving accurate reference leaf area index maps for validation of moderate-resolution satellite LAI products. IEEE Trans. Geosci. Remote Sens. 2006, 44, 1866-1871.

66. Mu, X.; Shen, Q.; Li, Z.-L.; Yan, G.; Sobrino, J.A. A comparison of different optimization algorithms for retrieving aerosol optical depths from satellite data: An example of using a dual-angle algorithm. Int. J. Remote Sens. 2011, 32, 8949-8968.

67. Wu, H.; Tang, B.-H.; Li, C.; Li, Z.-L. Leaf Area Index Retrieval from Remotely Sensed Data: Scaling Effect and Propagation Mechanisms. In Proceedings of the 2010 IEEE International Geoscience and Remote Sensing Symposium (IGARSS), Honolulu, HI, USA, 25-30 July 2010; pp. 2668-2671.

68. Wu, H.; Tang, B.-H.; Li, Z.-L. Impact of nonlinearity and discontinuity on the spatial scaling effects of the leaf area index retrieved from remotely sensed data. Int. J. Remote Sens. 2013, 34, 3503-3519.

69. Chen, J.M.; Dend, F.; Chen, M. Locally adjusted cubic-spline capping for reconstructing seasonal trajectories of a satellite-derived surface parameter. IEEE Trans. Geosci. Remote Sens. 2006, 44, 2230-2238.

(C) 2014 by the authors; licensee MDPI, Basel, Switzerland. This article is an open access article distributed under the terms and conditions of the Creative Commons Attribution license (http://creativecommons.org/licenses/by/3.0/). 